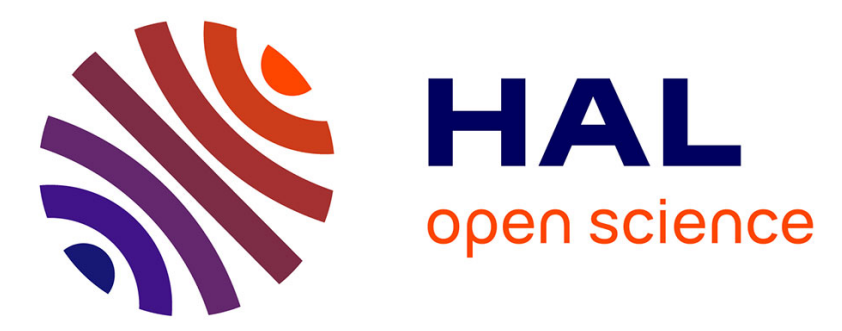

\title{
Spectroscopic Sensing of O2-C2H2-C2H4 flames for diamond growth using femtosecond filamentation
}

Yunshen Zhou, Mengmeng Wang, Yao Lu, Jean-François Silvain, Yongfeng Lu

\section{To cite this version:}

Yunshen Zhou, Mengmeng Wang, Yao Lu, Jean-François Silvain, Yongfeng Lu. Spectroscopic Sensing of $\mathrm{O} 2-\mathrm{C} 2 \mathrm{H} 2-\mathrm{C} 2 \mathrm{H} 4$ flames for diamond growth using femtosecond filamentation. Crystal Growth \& Design, 2017, 17 (6), pp.3443-3449. 10.1021/acs.cgd.7b00385 . hal-01549533

\section{HAL Id: hal-01549533 \\ https://hal.science/hal-01549533}

Submitted on 12 Mar 2021

HAL is a multi-disciplinary open access archive for the deposit and dissemination of scientific research documents, whether they are published or not. The documents may come from teaching and research institutions in France or abroad, or from public or private research centers.
L'archive ouverte pluridisciplinaire HAL, est destinée au dépôt et à la diffusion de documents scientifiques de niveau recherche, publiés ou non, émanant des établissements d'enseignement et de recherche français ou étrangers, des laboratoires publics ou privés. 


\title{
Spectroscopic sensing of $\mathrm{O}_{2}-\mathrm{C}_{2} \mathrm{H}_{2}-\mathrm{C}_{2} \mathrm{H}_{4}$ flames for diamond growth using femtosecond filamentation
}

\author{
Yun Shen Zhou, ${ }^{1,+}$ Meng Meng Wang, ${ }^{1,+}$ Yao Lu, ${ }^{1}$ Jean François Silvain, ${ }^{2}$ and Yong Feng Lu ${ }^{1, *}$ \\ 1 Department of Electrical and Computer Engineering, University of Nebraska - Lincoln, \\ Lincoln, NE 68588-0511, USA
}

2 Institut de Chimie de la Matière Condensée de Bordeaux - ICMCB-CNRS 87, Avenue du Docteur Albert Schweitzer, F-33608 Pessac Cedex, France.

\begin{abstract}
The influence of the resonant vibrational excitation of the ethylene wagging mode $\left(v 7,949.3 \mathrm{~cm}^{-1}\right)$ on the combustion chemical vapor deposition of diamond was studied via femtosecond laser-induced filamentation (FLIF) spectroscopy. The $\mathrm{O}_{2}-\mathrm{C}_{2} \mathrm{H}_{2}-\mathrm{C}_{2} \mathrm{H}_{4}$ flame filaments were sampled within the diamond-formation zones to investigate the evolution of the diamondformation-related species. In addition to higher diamond growth rates, increasing the incident laser power density led to the transitions of diamond crystal facets and quality as the results of competition between carbon-containing and $\mathrm{OH}$-containing species. Evaluated using the $\mathrm{C}_{2}: \mathrm{OH}$ number density ratio, $\{100\}$-faceted diamond crystals were obtained at the $\mathrm{C}_{2}: \mathrm{OH}$ ratio of 110.00 , while $\{111\}$-faceted diamond crystals were produced at the $\mathrm{C}_{2}: \mathrm{OH}$ ratio of 133.34 .
\end{abstract}

Correspondence should be addressed to Prof. Yong Feng Lu, Department of Electrical and Computer Engineering, University of Nebraska - Lincoln, Lincoln, NE 68588-0511, USA

Tel.: +1-402-472-8323. Fax: +1-402-472-4732. Email: ylu2@unl.edu.

Homepage: http://lane.unl.edu. 


\title{
Spectroscopic sensing of $\mathrm{O}_{2}-\mathrm{C}_{2} \mathrm{H}_{2}-\mathrm{C}_{2} \mathrm{H}_{4}$ flames for diamond growth using femtosecond filamentation
}

Yun Shen Zhou, ${ }^{1,+}$ Meng Meng Wang, ${ }^{1,+}$ Yao Lu, ${ }^{1}$ Jean François Silvain, ${ }^{2}$ and Yong Feng Lu ${ }^{1, *}$

1 Department of Electrical and Computer Engineering, University of Nebraska - Lincoln, Lincoln, NE 68588-0511, USA

2 Institut de Chimie de la Matière Condensée de Bordeaux - ICMCB-CNRS 87, Avenue du Docteur Albert Schweitzer, F-33608 Pessac Cedex, France.

\begin{abstract}
The influence of the resonant vibrational excitation of the ethylene wagging mode $\left(v 7,949.3 \mathrm{~cm}^{-1}\right)$ on the combustion chemical vapor deposition of diamond was studied via femtosecond laser-induced filamentation (FLIF) spectroscopy. The $\mathrm{O}_{2}-\mathrm{C}_{2} \mathrm{H}_{2}-\mathrm{C}_{2} \mathrm{H}_{4}$ flame filaments were sampled within the diamond-formation zones to investigate the evolution of the diamondformation-related species. In addition to higher diamond growth rates, increasing the incident laser power density led to the transitions of diamond crystal facets and quality as the results of competition between carbon-containing and $\mathrm{OH}$-containing species. Evaluated using the $\mathrm{C}_{2}: \mathrm{OH}$ number density ratio, $\{100\}$-faceted diamond crystals were obtained at the $\mathrm{C}_{2}: \mathrm{OH}$ ratio of 110.00 , while $\{111\}$-faceted diamond crystals were produced at the $\mathrm{C}_{2}: \mathrm{OH}$ ratio of 133.34 .
\end{abstract}

KEYWORDS: diamond, femtosecond laser-induced filamentation, resonant vibrational excitation. 


\section{Introduction}

As one of the hardest materials, diamond exhibits a wide range of "the most and best" properties. ${ }^{1-6}$ Therefore, diamond has been considered as an ideal material for diverse applications. To satisfy the diamond crave, numerous synthetic methods have been developed, including high pressure high temperature (HPHT), hot filament chemical vapour deposition (HFCVD), microwave CVD (MWCVD), and combustion CVD. ${ }^{1-7}$ Among the reported synthetic methods, combustion CVD has the advantages of simplicity, cost-effectiveness, open-air operation, and high

growth rates. ${ }^{7}$ Recently, a laser-assisted combustion CVD of diamond was reported. ${ }^{8-12}$ By resonantly exciting ethylene molecules, laser energy was efficiently coupled into the oxygenhydrocarbon flames, and led to significantly promoted diamond growth rates and quality. ${ }^{11}$ Diamond films containing crystals of preferential orientations and uniform crystalline facets were obtained. ${ }^{11}$ However, it remains unclear the mechanisms underpinning the improvements. Optical emission spectroscopic (OES) investigations of the oxygen-hydrocarbon flames were conducted ${ }^{11-}$ 13 and found out that a resonant vibrational excitation was highly efficient in energy coupling, increasing flame temperatures, and accelerating the combustion reactions. Diamond surface morphologies, dominant crystalline orientations, growth rates, and quality were closely related the species in the flames. ${ }^{11-13}$ However, OES collects the total amounts of emissions from an observation window, and delivers accumulative results of the flames. Due to the complexities of the combustion chemistry, transport processes, and aerodynamics, it is very challenging to distinguish whether the improved diamond growth is resulted from the thermal effects or the kinetic effects using the OES only. Therefore, real-time and in situ observations of the temporal evolution of the available species in the oxygen-hydrocarbon flames are critical for understanding 
the mechanisms underpinning the laser-assisted combustion CVD of diamond and eventually realizing growth control.

Femtosecond (fs) laser induced filamentation (FLIF) is a self-guided plasma channel resulted from a dynamic competition between the self-focusing by optical Kerr effect and plasma defocusing due to multiphoton ionization. ${ }^{14,15}$ In particular, the laser intensity inside the plasma channel is strong enough to induce ionization and fragmentation of molecules and trig a fingerprint fluorescence emission from the ionized molecules or fragments that can be used for identifying parent molecules. ${ }^{16} \mathrm{Li}$ et al used FLIF to detect the distributions of combustion intermediates and observed fluorescence emissions from $\mathrm{CH}, \mathrm{CN}, \mathrm{NH}, \mathrm{OH}$, and $\mathrm{C}_{2}$ free radicals. ${ }^{17,18}$ It is well accepted that the FLIF-induced fluorescence comes from the interactions of the FLIF with the intermediates rather than parent precursor fragments. ${ }^{18}$ Therefore, FLIF provides a viable approach to achieve site-selective detection of available species in combustion flames.

In this study, a spectroscopic study of the $\mathrm{O}_{2}-\mathrm{C}_{2} \mathrm{H}_{2}-\mathrm{C}_{2} \mathrm{H}_{4}$ flames was conducted using the FLIF sensing method. Emissions from flame filaments within the diamond-formation zones were investigated when the wagging mode of ethylene molecules $\left(v 7,949.3 \mathrm{~cm}^{-1}\right)$ was resonantly excited at $10.532 \mu \mathrm{m}$ at various laser power densities. Typical combustion intermediates including $\mathrm{OH}$, $\mathrm{CN}, \mathrm{CH}, \mathrm{C}_{2}, \mathrm{C}_{3}$, and $\mathrm{H}_{\alpha}$ were observed. It was found that increasing the incident laser power density led to higher diamond growth rates, transitions of diamond crystal facets, and diamond quality as the results of competition between carbon-containing and $\mathrm{OH}$-containing species. Evaluated using the $\mathrm{C}_{2}: \mathrm{OH}$ number density ratio, $\{100\}$-faceted diamond crystals were obtained at the $\mathrm{C}_{2}: \mathrm{OH}$ ratio of 110.00 , while $\{111\}$-faceted diamond crystals were produced at the $\mathrm{C}_{2}: \mathrm{OH}$ ratio of 133.34 .

\section{Experimental section}


A laser-assisted combustion CVD system, ${ }^{8-12}$ was used for depositing diamond. A gas mixture containing $\mathrm{O}_{2}, \mathrm{C}_{2} \mathrm{H}_{2}$, and $\mathrm{C}_{2} \mathrm{H}_{4}$ (with corresponding flow rates of $0.62,0.62$ and 1.2 standard liters per minute, respectively) was used as the precursors to fuel the flames and deposit diamond. Ethylene was added due to its strong infrared absorptions within the $\mathrm{CO}_{2}$ laser wavelength range to couple laser energy into the flames. Tungsten carbide (WC) plates (BS-6S, Basic Carbide Corp.) were used as the substrates for diamond deposition and mounted on a water-cooled translational stage. The substrate temperature was kept between 770 and $780^{\circ} \mathrm{C}$. The distance between the inner flame tips and substrate surfaces was fixed at $0.5 \mathrm{~mm}$. A wavelength-tuneable continuous-wave $\mathrm{CO}_{2}$ laser (PRC Inc, STS 1000, $9.2 \sim 10.9 \mu \mathrm{m}$ ) was used as the irradiation source to excite the $\mathrm{C}_{2} \mathrm{H}_{4}$ molecules. Based on the available emission lines from the $\mathrm{CO}_{2}$ laser, the $\mathrm{CH}_{2}$-wagging mode (a type c fundamental band, $v 7$, at $949.3 \mathrm{~cm}^{-1}$ ) of ethylene molecules was selected for the investigations. Laser irradiation at $10.532 \mu \mathrm{m}$, which precisely matched the $v_{7}$ mode, was projected right beneath the torch nozzle, and kept normally to the flame axis and parallel to the substrate surface. The laser beam was focused using a $\mathrm{ZnSe}$ convex lens (focal length $=254 \mathrm{~mm}$ ) to $\sim 2.0$ $\mathrm{mm}$ in diameter and fully covered the inner flames. The laser power was increased from 0.0 to $1000.0 \mathrm{~W}$ with a step of $100 \mathrm{~W}$ for each measurement, corresponding to the laser power densities from 0.0 to $33.0 \mathrm{~kW} / \mathrm{cm}^{2}$. The diamond deposition time was fixed at $1.0 \mathrm{~h}$ for all samples. 


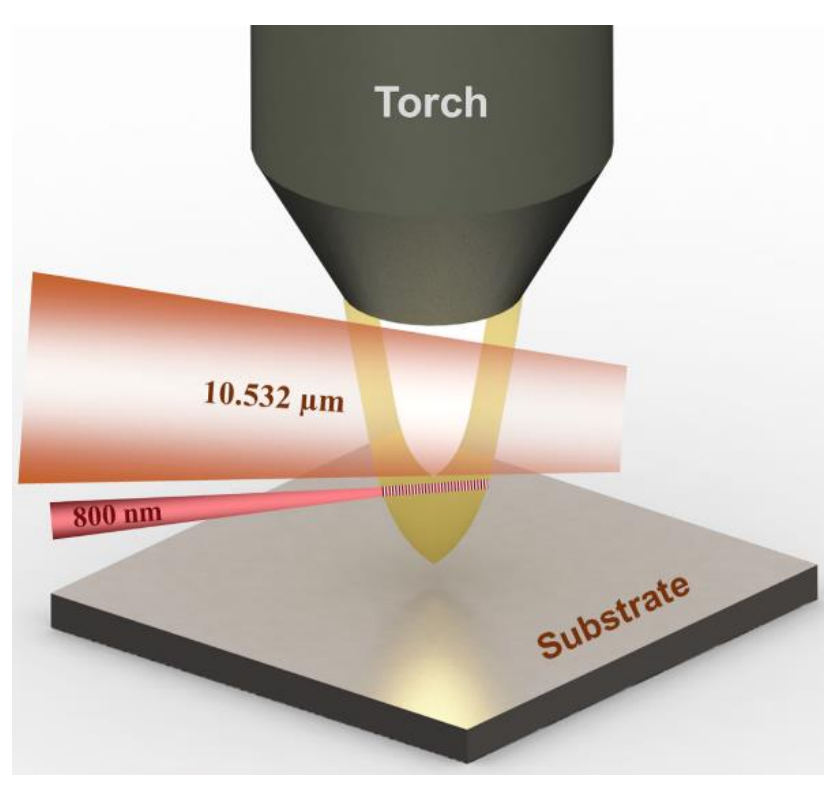

Figure 1. A schematic diagram showing the laser-assisted combustion CVD of diamond and FLIF sensing of the flame.

For the FLIF sensing, a Ti:sapphire fs laser (Legend F, Coherent Inc.) with a centre wavelength at $800 \mathrm{~nm}$ and a pulse duration of $150 \mathrm{fs}$ was deployed as the irradiation source to excite the species in the flame filaments, as shown in Figure 1. The laser pulse energy was fixed at $600 \mu \mathrm{J}$. A lens with a focal length of $200 \mathrm{~mm}$ was used to focus the laser beam. The emission spectra of the species in the flame was taken by a spectrograph (Shamrock 303i, Andor Inc.) equipped with an intensified CCD (ICCD, Model DH 712, Andor Inc.). The flame emission was collected by two lenses and focused onto the spectrograph slit. The spectrograph was equipped with three gratings of 150,600 , and 2400 lines/mm, corresponding to spectral resolutions of $0.88,0.21$, and $0.05 \mathrm{~nm}$, respectively. The flame images were taken by the same ICCD equipped with a Nikkor lens. The spectral and image recordings were implemented with a gate delay of $25 \mathrm{~ns}$ with respect to the starting of the fs laser pulses. The measurement gate width was 30 ns. Each measurement was accumulated for 200 times. 
Surface morphologies of the diamond films were characterized using a scanning electron microscope (SEM; XL-30, Phillips Electronics). The diamond film thickness was measured using a 3D optical surface profiler (NewView 8000, Zygo Inc.). The diamond quality was evaluated using a Raman spectrometer (inVia, Renishaw Ltd.), in which an argon-ion laser $(\lambda=514.5 \mathrm{~nm})$ was used as the irradiation source at a fixed output power of $50 \mathrm{~mW}$. A $20 \mathrm{X}$ objective lens was used to focus the argon-ion laser beam to a spot of approximately $5 \mu \mathrm{m}$ in diameter.

\section{Results and discussion Diamond film characterization}

Figure 2 shows SEM micrographs of the diamond films deposited on the WC substrates under different $\mathrm{CO}_{2}$ laser power densities. Diamond grains of random sizes and orientations are observed on the diamond film deposited without the $\mathrm{CO}_{2}$ laser irradiation (Figure 2a). By introducing the $\mathrm{CO}_{2}$ laser irradiation $(\lambda=10.532 \mu \mathrm{m})$, two noticeable changes are observed. The first is the increased diamond grain sizes with the augment of the $\mathrm{CO}_{2}$ laser power density, as observed from Figures $2 b$ to $2 \mathrm{i}$. Secondary diamond growth is observed in Figure $2 \mathrm{j}$ when the laser power density reached $29.7 \mathrm{~kW} / \mathrm{cm}^{2}$ and higher, in which cauliflower-like grains are observed due to the growth of small diamond crystals from the existing crystals. The second is the diamond crystalline orientations. In Figures $2 \mathrm{a}$ and $2 \mathrm{~b}$, diamond crystals of random crystalline orientations are observed. In Figure 2c (laser power density of $6.6 \mathrm{~kW} / \mathrm{cm}^{2}$ ), diamond crystals with prevailing $\{100\}$ faces are observed. Between the laser power density of 9.9 and $19.8 \mathrm{~kW} / \mathrm{cm}^{2}$, the diamond films are dominated by cuboctahedron diamond crystals showing $\{111\}$ faces, as observed in Figures $2 \mathrm{~d}$ to $2 \mathrm{~g}$. In Figure $2 \mathrm{~h}$ (laser power density of $23.1 \mathrm{~kW} / \mathrm{cm}^{2}$ ), the diamond film is converted back to $\{100\}$ faces again. At the laser power densities higher than $19.8 \mathrm{~kW} / \mathrm{cm}^{2}$, diamond grains started to coalesce and form dense diamond films as shown in Figures $2 \mathrm{~h}$ and $2 \mathrm{i}$. 

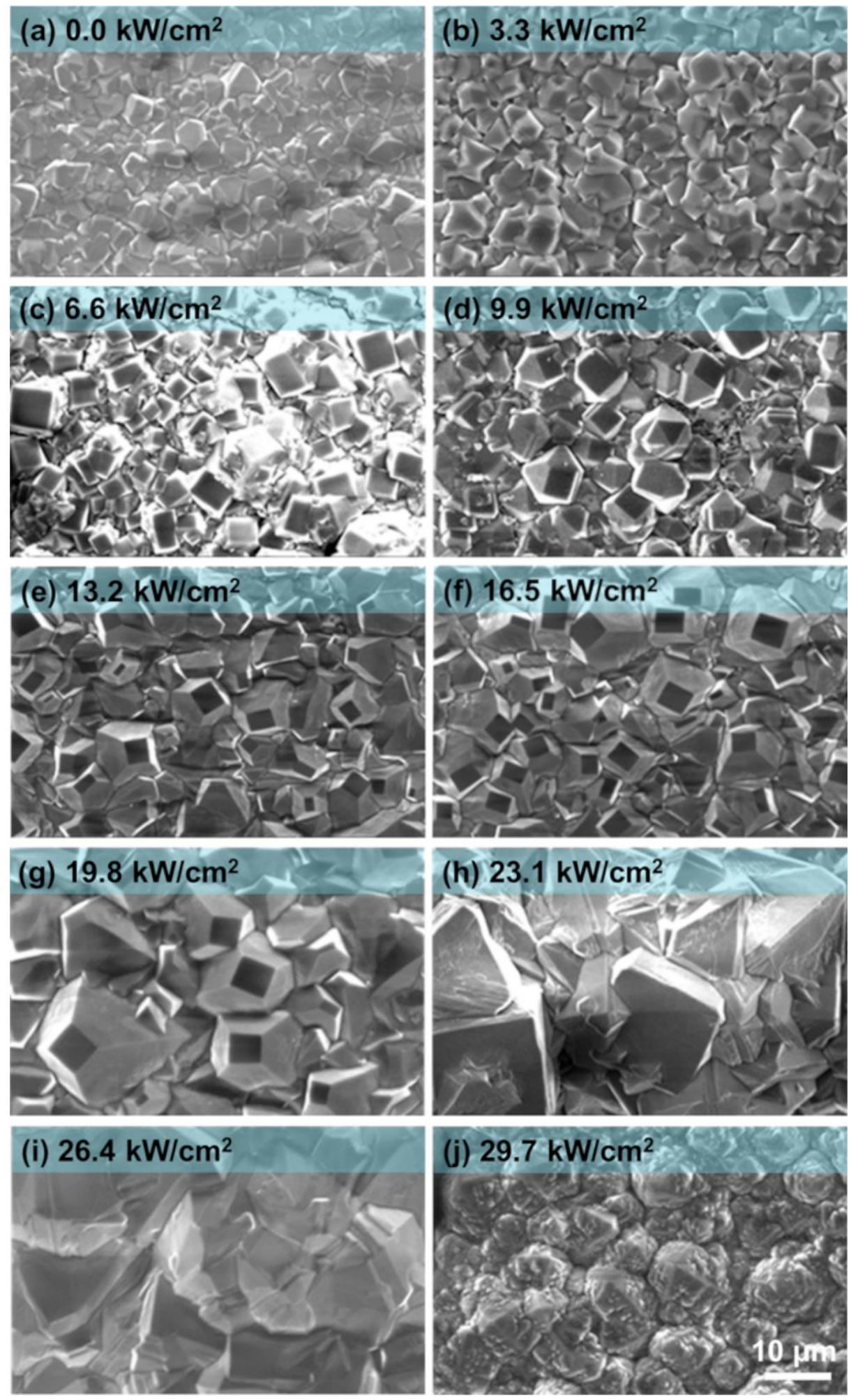

Figure 2. SEM micrographs showing morphologies of the diamond films deposited under different laser power densities from 0.0 to $29.7 \mathrm{~kW} / \mathrm{cm}^{2}$. 
The average diamond film growth rates were calculated by dividing the film thicknesses by corresponding deposition times. The dependence of the diamond film growth rate on the laser power density is plotted in Figure 3, showing a proportional increase as the $\mathrm{CO}_{2}$ laser power density rises from 3.3 to $29.7 \mathrm{~kW} / \mathrm{cm}^{2}$, demonstrating promoted diamond growth rate (or carbon deposition rate) under the resonant vibrational excitation.

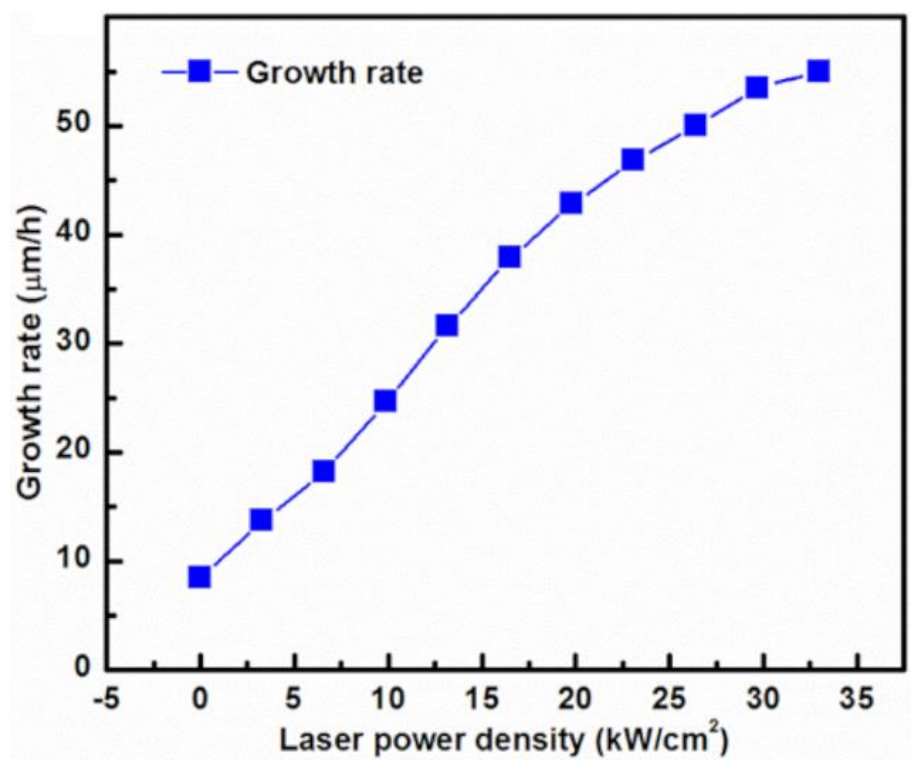

Figure 3. The diagram showing the dependence of the diamond growth rate on the incident $\mathrm{CO}_{2}$ laser power density.

The diamond quality was evaluated using Raman spectroscopy. Figure 4a shows a typical Raman spectrum of the diamond films featuring a sharp diamond peak at $1332 \mathrm{~cm}^{-1}$, a broad Dband centred at $1370 \mathrm{~cm}^{-1}$, and a broad G-band centred at $1550 \mathrm{~cm}^{-1}$. The broad D-band was ascribed to the breathing mode of $s p^{2}$ carbon atom rings reflecting disordered carbon phases in the diamond films. The broad G-band is attributed to the bond stretching of $s p^{2}$ carbon atom pairs indicating the existence of graphitic carbons in the diamond matrix. By fitting the spectrum using the three peaks, as shown in Figure 4a, diamond quality was evaluated using the following equation: 19,20 


$$
Q_{[514 \mathrm{~nm}]}=\left[I_{D} /\left(I_{D}+I_{C} / 233\right)\right] 100 \%
$$

where $I_{D}$ is the intensity of the diamond peak, and $I_{C}$ is the total intensity of nondiamond carbon peaks. The dependence of the diamond quality $(Q)$ on the laser power density was plotted in Figure 4b. The highest quality factor of $99 \%$ was obtained at the laser power density of $23.1 \mathrm{~kW} / \mathrm{cm}^{2}$ and dropped sharply below $90 \%$ by continuously increasing the laser power density.
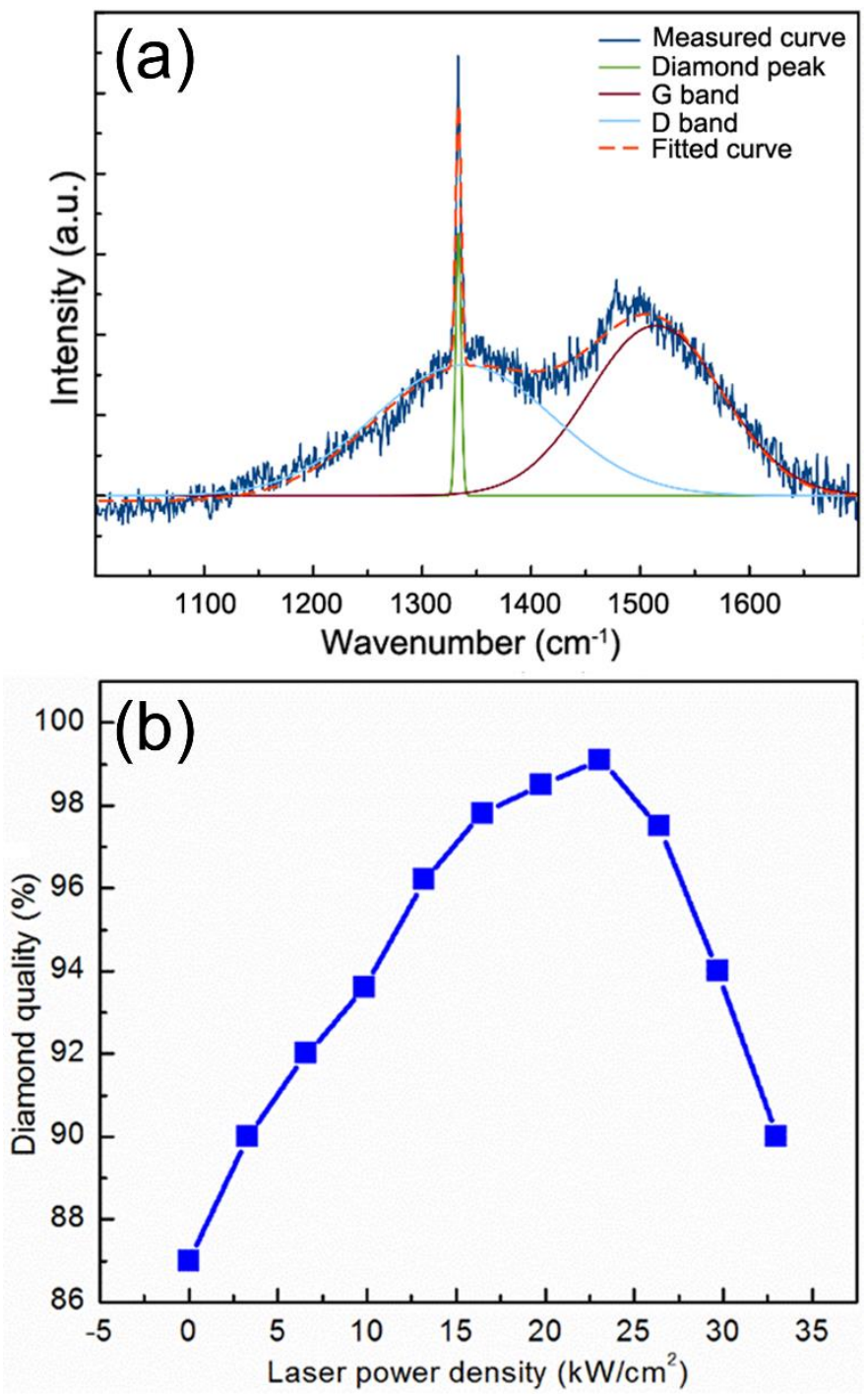

Figure 4. (a) A typical Raman spectrum of the diamond films deposited without resonant laser excitation; and (b) a diagram showing the dependence of the diamond film quality on the incident laser power density. 


\section{FLIF sensing of the diamond-formation zone in the flames}

To investigate the diamond deposition mechanism in the laser-assisted combustion CVD processes, the FLIF sensing method was deployed to study the diamond-formation zones in the $\mathrm{O}_{2}-\mathrm{C}_{2} \mathrm{H}_{2}-\mathrm{C}_{2} \mathrm{H}_{4}$ flames. In our studies, it was found out that different carbon products, such as carbon soot, carbon nanohorns, carbon nano-onions, and diamond, were collected at different flame zones. The results implied that corresponding chemical dynamics and kinetics were dissimilar at different flame zones. To study corresponding diamond formation mechanisms, the fs-laser pulses were projected into the flame diamond-formation zone, $0.5 \mathrm{~mm}$ below the inner flame (Figure 5), and induced the filament of the diamond-formation zone. The dashed line in Figure 5 represents the position of the torch nozzle, from which the gas mixtures were ejected and the flames ignited. As observed in Figure 5, the flame becomes brighter, shorter and wider when the $\mathrm{CO}_{2}$ laser power density increases. Generally speaking, the colour and brightness of a flame represents emission intensity that is the function of the temperature and particle density of the observed zone. A high count refers to a high temperature and particle density in that area. The flame length and width define the reaction volume in which combustion reactions occur. Therefore, brighter emissions and decreased flame volumes indicated accelerated chemical reactions with the increased laser power densities as shown in Figure 5. The average length of the FLIF filaments is around $4 \mathrm{~mm}$, which is long enough to cover the diamond-formation regions as shown in Figure 5. The diameters of the FLIF filaments are around $200 \mu \mathrm{m}$. To achieve equally comparable spectra of the flames, the spectra were taken at the centre areas of the feathers. It should be noted that the image recording was performed at a gate width of $20 \mathrm{~ns}$, therefore, the images show the brightest inner flame parts but other parts such as the feathers and the outer flames are not shown in Figure 5. 


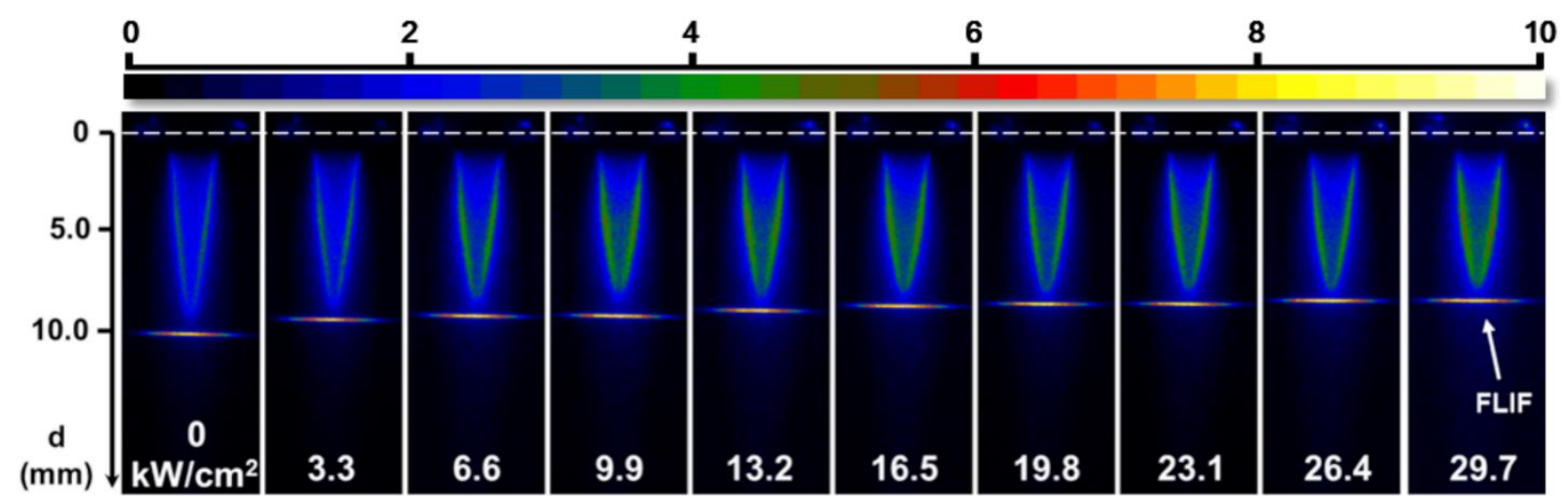

Figure 5. Images of the fs-laser induced filaments in the $\mathrm{O}_{2}-\mathrm{C}_{2} \mathrm{H}_{2}-\mathrm{C}_{2} \mathrm{H}_{4}$ flames under different laser power densities. The dashed line represents the position of the torch nozzle. The scale bar shows the colour and brightness of the flames.

Figure 6 shows a typical FLIF-induced spectrum of the diamond-formation zone in an $\mathrm{O}_{2}-\mathrm{C}_{2} \mathrm{H}_{2}$ $\mathrm{C}_{2} \mathrm{H}_{4}$ flame, in which $\mathrm{OH}, \mathrm{CN}, \mathrm{C}_{3}, \mathrm{CH}, \mathrm{C}_{2}$, and $\mathrm{H}_{\alpha}$ are observed. Table 1 lists the transitions and corresponding peaks of the detected emissive radicals, including $\mathrm{OH}, \mathrm{CN}, \mathrm{C}_{3}, \mathrm{CH}, \mathrm{C}_{2}$ and $\mathrm{H}_{\alpha}$.

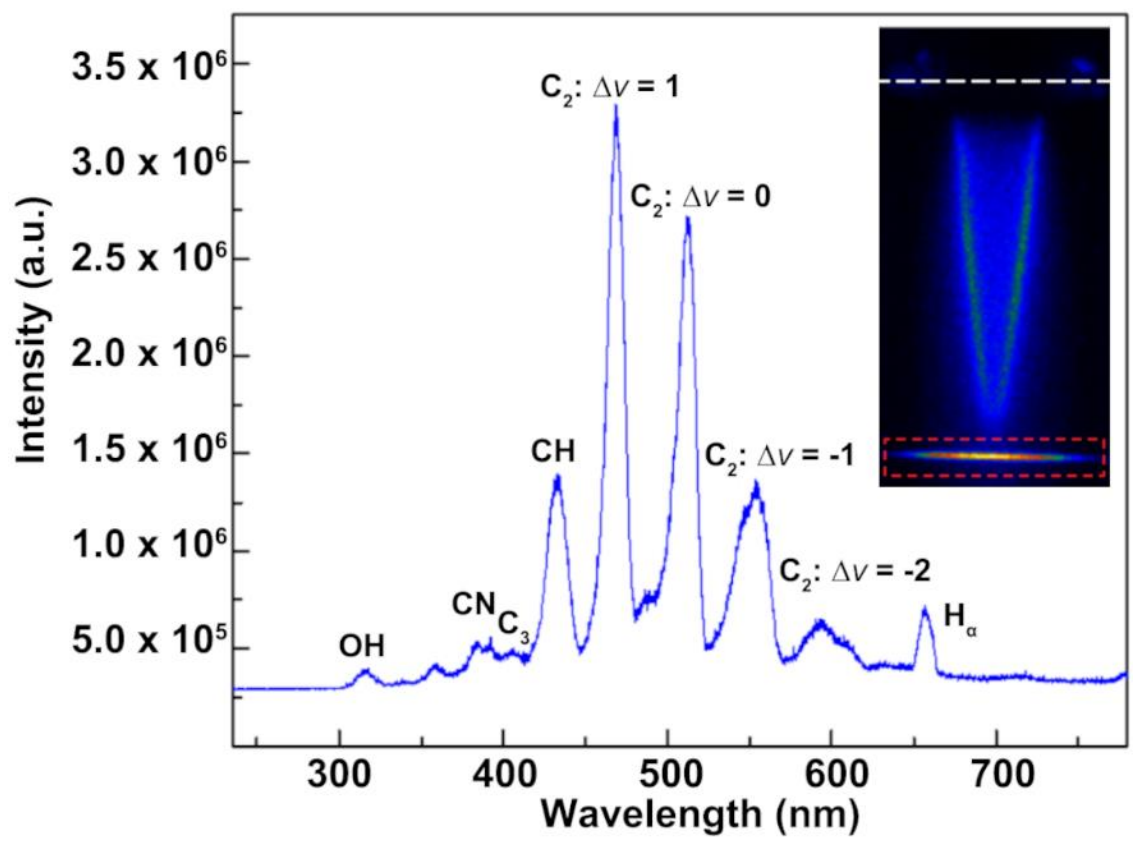

Figure 6. A typical FILF spectrum of the flame filament (as shown in the inset) at the diamond growth region without the vibrational excitation. 
Table 1. Detected emissive radicals and corresponding transitions. ${ }^{21-25}$

\begin{tabular}{|c|c|c|}
\hline Radical & Transition & Peak (nm) \\
\hline $\mathrm{OH}$ & $\mathrm{A}^{2} \Sigma-\mathrm{X}^{2} \Pi$ & $309.1(\Delta \mathrm{v}=0)$ \\
\hline $\mathrm{CN}$ & $\mathrm{B}^{2} \Sigma^{+}-\mathrm{X}^{2} \Sigma^{+}$ & $388.3(\Delta \mathrm{v}=0), 421.6(\Delta \mathrm{v}=-1)$ \\
\hline $\mathrm{C}_{3}$ & $\mathrm{~A}^{1} \prod_{\mathrm{u}}-\mathrm{X}^{1} \Sigma_{\mathrm{g}}^{+}$ & $405(\Delta \mathrm{v}=0)$ \\
\hline $\mathrm{CH}$ & $\mathrm{A}^{2} \Delta-\mathrm{X}^{2} \prod_{\mathrm{r}}$ & $431.4(\Delta \mathrm{v}=0)$ \\
\hline $\mathrm{C}_{2}$ & $\mathrm{~d}^{3} \prod_{\mathrm{g}}-\mathrm{a}^{3} \prod_{\mathrm{u}}$ & $473.7(\Delta \mathrm{v}=+1), 516.5(\Delta \mathrm{v}=0), 563.6(\Delta \mathrm{v}=-1)$ \\
\hline $\mathrm{H}_{\alpha}$ & $3 \mathrm{p}^{2} \mathrm{P}_{1 / 2}^{0_{1}}-2 \mathrm{~s}^{2} \mathrm{~S}_{1 / 2}$ & 656.3 \\
\hline
\end{tabular}

Figure 7 shows the time-resolved FLIF-induced spectra of the diamond-formation zone in an $\mathrm{O}_{2}-\mathrm{C}_{2} \mathrm{H}_{2}-\mathrm{C}_{2} \mathrm{H}_{4}$ flame resonantly excited by the $\mathrm{CO}_{2}$ laser at a power density of $29.7 \mathrm{~W} / \mathrm{cm}^{2}$. Emissions from $\mathrm{CH}(431.4 \mathrm{~nm}), \mathrm{C}_{2}(473.7,516.5$, and $563.6 \mathrm{~nm})$ and $\mathrm{H}_{\alpha}(656.3 \mathrm{~nm})$ are observed without obvious Bremsstrahlung emission. The strongest emission is observed at 20 ns delay with respect to the ignition of the fs laser pulse showing a prominently strong $\mathrm{H}_{\alpha}$ peak. The peak intensities drop dramatically between the delay interval of 20 and $40 \mathrm{~ns}$, and become almost constant after $40 \mathrm{~ns}$. The spectra collected after $40 \mathrm{~ns}$ demonstrate the identical peaks and similar peak intensities as the spectrum collected at $0 \mathrm{~ns}$, therefore, are ascribed to the flame emissions rather than the FILF filaments.

It is recognized that the diamond formation processes in a typical CVD process involve both carbon deposition and etching processes simultaneously. Available radicals and corresponding concentrations are critical in deciding reaction kinetics and dynamics of the diamond-formation processes. Generally speaking, $\mathrm{OH}$ radicals are active etchant to remove non-diamond carbons, ${ }^{26}$ therefore, improve the diamond quality. However, an excessive amount of $\mathrm{OH}$ radicals can also 
retard the diamond deposition, due to the formation of vacant growth sites on diamond surfaces. $\mathrm{CH}$ radicals are regarded as a beneficial one for the formation of diamond. ${ }^{24-28} \mathrm{C}_{2}$ radicals are key gradients for carbon deposition and diamond formation. ${ }^{29,30}$ However, $\mathrm{C}_{2}$ accumulation can lead to either graphite or diamond. Therefore, a fine balance between $\mathrm{OH}$ and $\mathrm{C}_{2}$ radicals is critical for controlling diamond deposition. $\mathrm{H}_{\alpha}$ radicals are suggested coming from the flame produced $\mathrm{H}_{2} \mathrm{O}$ molecules, therefore, can be treated as an indicator of the combustion reactions, i.e. the higher $\mathrm{H}_{\alpha}$ concentration, the more vigorous combustion reaction. ${ }^{24-30}$ The optical emission signal of a given electronic transition between an excited state $\mathrm{u}$ and a ground state $\mathrm{g}$ during a time interval $\mathrm{t}_{\mathrm{g}}$, can be calculated via following equation: ${ }^{31}$

$$
\mathrm{S}=\mathrm{A}_{\mathrm{ug}} \cdot \mathrm{n}_{\mathrm{exc}} \cdot \mathrm{V}_{\mathrm{fl}} \cdot \Omega / 4 \pi \cdot \varepsilon \cdot \eta \cdot \mathrm{tg}_{\mathrm{g}}
$$

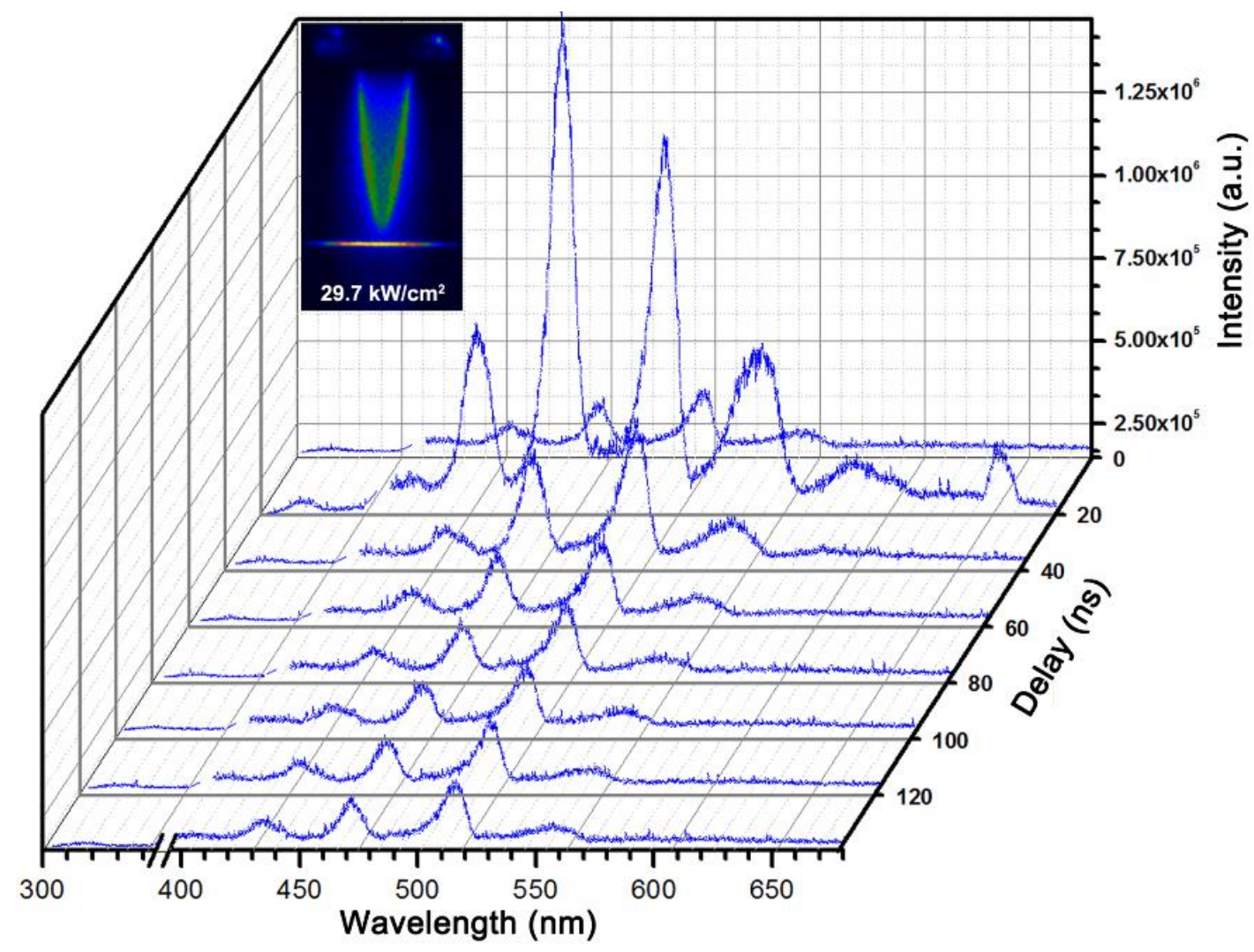

Figure 7. Time resolved spectra of the flame filament (as shown in the inset) induced by fs-laser irradiation at the diamond-formation zone at the $\mathrm{CO}_{2}$ laser power intensity of $29.7 \mathrm{~kW} / \mathrm{cm}^{2}$. 
where $A_{u g}$ is the Einstein emission coefficient of the observed vibrational band $\left(\mathrm{s}^{-1}\right), \mathrm{n}_{\mathrm{exc}}$ is the number density of the excited species $\left(\mathrm{cm}^{-3}\right)$, and $\mathrm{V}_{\mathrm{fl}}$ is the observed volume. The rest parameters are given by the optics and electronics in the detection of the emission signals, in which $\Omega$ is the solid angle, $\varepsilon$ is the transmission efficiency of the optics, and $\eta$ is the photoelectric conversion. Therefore, equation (2) can be simplified to

$$
\mathrm{S}=\mathrm{A}_{\mathrm{ug}} \cdot \mathrm{n}_{\mathrm{exc}} \cdot \mathrm{B}
$$
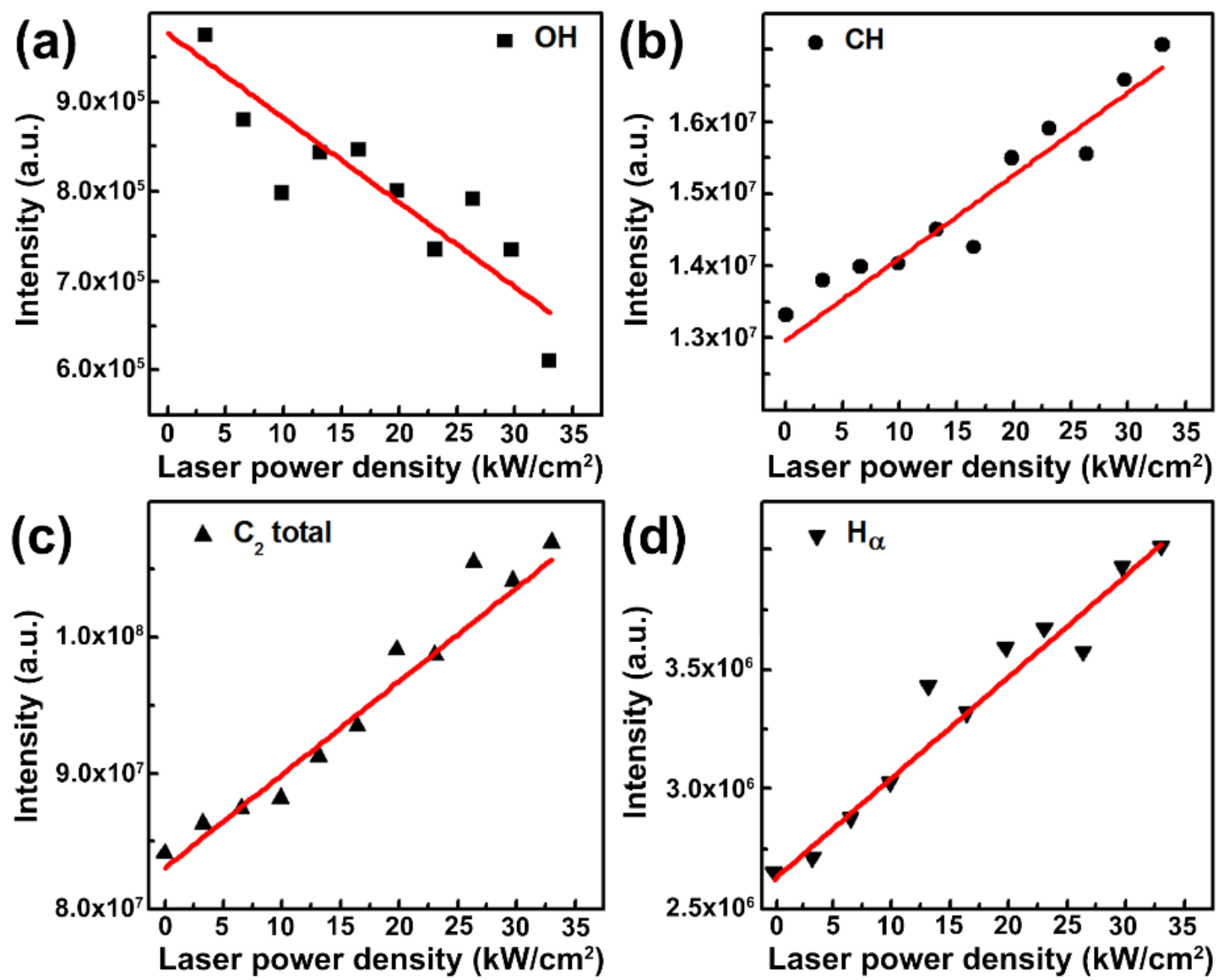

Figure 8. Emission intensities of (a) $\mathrm{OH}$, (b) $\mathrm{CH}$, (c) $\mathrm{C}_{2}$, and (d) $\mathrm{H}_{\alpha}$ with respect to the $\mathrm{CO}_{2}$ laser power density obtained from the FLIF filaments at $40 \mathrm{~ns}$ delay time.

where $\mathrm{B}$ is a constant for a settled experiment. Therefore, $\mathrm{S}$ is only related to the Einstein emission coefficient and the number density of the excited species. For a specific radical, the signal is proportional to its number density. Figure 8 plots the radical intensities of $\mathrm{OH}, \mathrm{CH}, \mathrm{C}_{2}$, and $\mathrm{H}_{\alpha}$ 
with respect to the $\mathrm{CO}_{2}$ laser power density obtained from the FLIF filaments at 40 ns delay time. As observed in Figure 8a, the intensity of the non-diamond-carbon etchant, $\mathrm{OH}$, is inversely proportional to the $\mathrm{CO}_{2}$ laser power density, indicating restrained $\mathrm{OH}$ radical formation and reduced carbon-etching rates with the augment of the $\mathrm{CO}_{2}$ laser power density. The intensities of carbon-containing radicals, i.e. $\mathrm{CH}$ (Figure $8 \mathrm{~b}$ ) and $\mathrm{C}_{2}$ (Figure 8c), are proportional to the $\mathrm{CO}_{2}$ laser power density, indicating increased carbon deposition rates with the augment of the $\mathrm{CO}_{2}$ laser power density. Similarly, the intensity of $\mathrm{H}_{\alpha}$ rises with the growing $\mathrm{CO}_{2}$ laser power density, as shown in Figure 8d, demonstrating promoted combustion reactions.

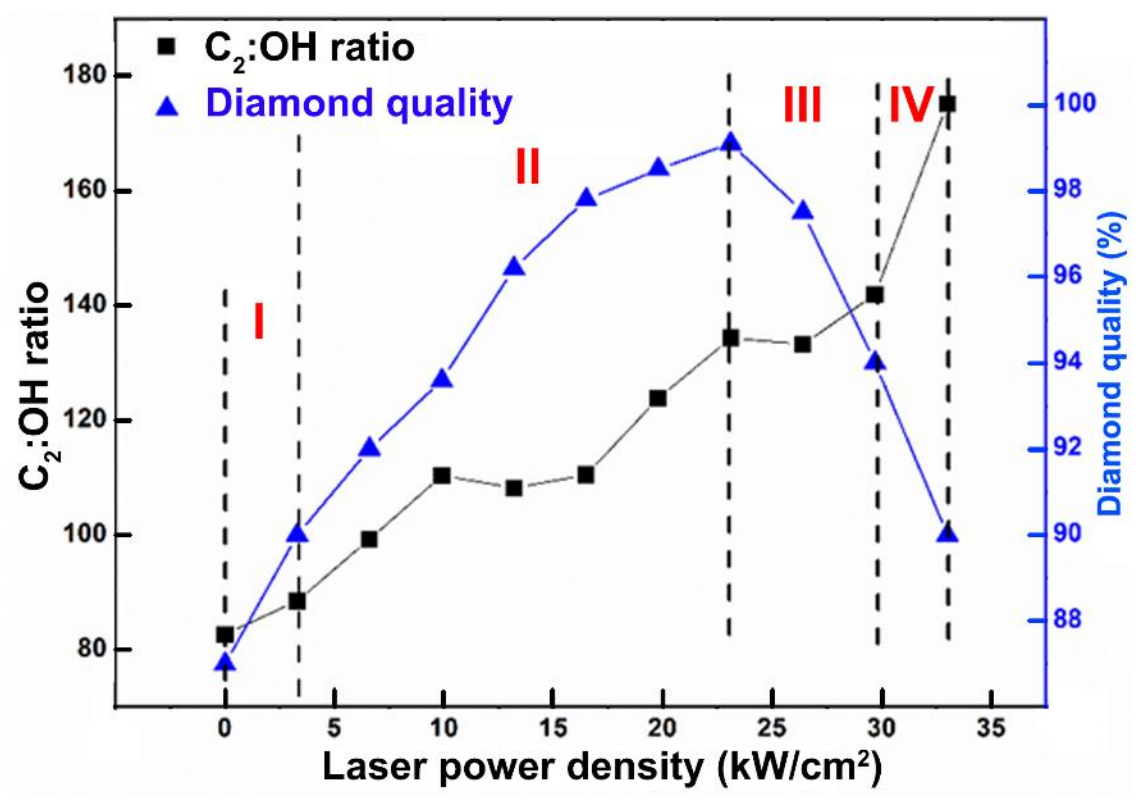

Figure 9. Dependence of $\mathrm{C}_{2}: \mathrm{OH}$ ratio and diamond quality on the $\mathrm{CO}_{2}$ laser power density.

Since a fine balance between $\mathrm{OH}$ and $\mathrm{C}_{2}$ radicals is critical for controlling diamond deposition, it is reasonable to investigate the influence of the $\mathrm{CO}_{2}$ laser power density in determining the diamond deposition rate, crystalline morphology, and quality using $\mathrm{C}_{2}$ and $\mathrm{OH}$ signal intensity ratios $\left(\mathrm{C}_{2}: \mathrm{OH}\right.$ ratio) as shown in Figure 9. 
By combining Figures 2 and 9, the deposited diamond films experience four phases with the augment of the $\mathrm{CO}_{2}$ laser power density, including Phase-I $\left(0.0\right.$ to $\left.3.3 \mathrm{~kW} / \mathrm{cm}^{2}\right)$ : diamond grains of random sizes and crystalline orientations; Phase-II ( 3.3 to $\left.23.1 \mathrm{~kW} / \mathrm{cm}^{2}\right):\{111\}$-facet diamond crystals; Phase-III (23.1 to $\left.29.7 \mathrm{~kW} / \mathrm{cm}^{2}\right)$ : $\{100\}$-facet diamond crystals; and Phase-IV (> 29.7 $\mathrm{kW} / \mathrm{cm}^{2}$ ): cauliflower-like diamond.

As observed in Figure 9, the $\mathrm{C}_{2}: \mathrm{OH}$ ratio increases consistently with the augment of the $\mathrm{CO}_{2}$ laser power density, indicating the increased carbon deposition rates and reduced carbon etching rates. The results are consistent with the results listed in Figure 3, showing a consistently growing deposition rate. Two flat zones are observed, 9.9-16.5 and 23.1-26.4 kW/ $/ \mathrm{cm}^{2}$, in which the $\mathrm{C}_{2}: \mathrm{OH}$ ratio is kept almost constant at $110.00 \pm 1.05$ and $133.34 \pm 0.67$, respectively. By comparing with Figure 2, the first flat zone, 9.9-16.5 kW/ $\mathrm{cm}^{2}$, coincides with the dominant growth of $\{111\}$ faceted diamond crystals, and the second flat zone, $23.1-26.4 \mathrm{~kW} / \mathrm{cm}^{2}$, coincides with the dominant growth of $\{100\}$-faceted diamond crystals. That is saying when the $\mathrm{C}_{2}: \mathrm{OH}$ ratio is controlled near $110.00,\{111\}$-faceted diamond crystals will be expected. When the $\mathrm{C}_{2}: \mathrm{OH}$ ratio is controlled around $133.34,\{100\}$-faceted diamond crystals will be produced.

The diamond quality curve (the triangle dots and blue curve) plotted in Figure 9 increases consistently with the augment of the $\mathrm{CO}_{2}$ laser power density and reaches its maximum value at $23.1 \mathrm{~kW} / \mathrm{cm}^{2}$, i.e. $\mathrm{C}_{2}: \mathrm{OH}$ ratio of 133.34 . When the $\mathrm{CO}_{2}$ laser power density is higher than 23.1 $\mathrm{kW} / \mathrm{cm}^{2}$, the diamond quality decreases rapidly and continuously despite the formation of large diamond grains. Cauliflower-like diamond grains, which contain considerable amount nondiamond carbons, are formed at the $\mathrm{CO}_{2}$ laser power densities above $29.7 \mathrm{~kW} / \mathrm{cm}^{2}$. Therefore, it can be concluded that the $\mathrm{C}_{2}$ outperforms the $\mathrm{OH}$ at the $\mathrm{C}_{2}: \mathrm{OH}$ ratios above 133.34, resulting in the increased deposition of non-diamond carbons and significantly reduced diamond quality. 
The final diamond crystal morphology is determined by the growth competition between the $\{100\}$ and $\{111\}$ surfaces, i.e. $\mathrm{V}_{100}$ and $\mathrm{V}_{111}$ respectively, as expressed by the diamond growth

parameter, $\alpha=\sqrt{3} \frac{V_{100}}{V_{111}} \cdot{ }^{32}$ A crystal facet exhibited at the end of the diamond deposition process is the one with the lowest growth rate. In order to grow diamond crystals showing dominantly $\{100\}$ surfaces, $\mathrm{V}_{100}$ should be controlled lower than $\mathrm{V}_{111}$. Therefore, it can be referred from Figure 9 that $\mathrm{V}_{100}$ is higher than $\mathrm{V}_{111}$ at the $\mathrm{C}_{2}: \mathrm{OH}$ ratio around 110.00 , i.e. the $\mathrm{CO}_{2}$ laser powder density between 9.9 and $16.5 \mathrm{~kW} / \mathrm{cm}^{2}$, when $\{111\}$-faceted diamond crystals are dominant. While at the $\mathrm{C}_{2}: \mathrm{OH}$ ratio around 133.34 , i.e. the $\mathrm{CO}_{2}$ laser powder density between 23.1 and $26.4 \mathrm{~kW} / \mathrm{cm}^{2}, \mathrm{~V}_{111}$ is higher than $\mathrm{V}_{100}$, when $\{100\}$-faceted diamond crystals are dominant.

\section{Conclusions}

The effects of resonant vibrational excitation of $\mathrm{C}_{2} \mathrm{H}_{4}$ molecules in combustion deposition of diamond was investigated using FLIF induced species emission. Typical radicals in combustion reactions, including $\mathrm{OH}, \mathrm{CH}, \mathrm{C}_{2}$ and $\mathrm{H}_{\alpha}$, were observed. With the augment of the $\mathrm{CO}_{2}$ laser power density, number densities of the carbon-deposition-related radicals $\left(\mathrm{CH}\right.$ and $\left.\mathrm{C}_{2}\right)$ increased accordingly. The carbon-etchant radical $(\mathrm{OH})$ exhibited a reverse trend, decreasing consistently with the rising $\mathrm{CO}_{2}$ laser power density. By associating the $\mathrm{C}_{2}: \mathrm{OH}$ ratio with the $\mathrm{CO}_{2}$ laser power density, changes on the diamond growth rate, crystal morphology, and diamond quality were ascribed to the competing effects of $\mathrm{OH}$ and $\mathrm{C}_{2}$. Although the increasing $\mathrm{C}_{2}: \mathrm{OH}$ ratio with the augment of the $\mathrm{CO}_{2}$ laser power density resulted in the promoted carbon deposition rates, corresponding diamond quality started to decrease at the $\mathrm{C}_{2}: \mathrm{OH}$ ratio of 133.34. Diamond crystal morphology were controlled by tuning the $\mathrm{C}_{2}: \mathrm{OH}$ ratio. At the $\mathrm{C}_{2}: \mathrm{OH}$ ratio of $110.00,\{111\}-$ faceted diamond crystals were obtained. While at the $\mathrm{C}_{2}: \mathrm{OH}$ ratio of $133.34,\{100\}$-faceted diamond crystals were produced. Since the final diamond crystal morphology was determined by 
the growth competition between the $\{100\}$ and $\{111\}$ surfaces, i.e. $V_{100}$ and $V_{111}$ respectively, it was referred that $\mathrm{V}_{100}$ is higher than $\mathrm{V}_{111}$ at the $\mathrm{C}_{2}: \mathrm{OH}$ ratio around 110.00 , and $\mathrm{V}_{111}$ is higher than $\mathrm{V}_{100}$ at the $\mathrm{C}_{2}: \mathrm{OH}$ ratio around 133.34 . 


\section{FIGURES}

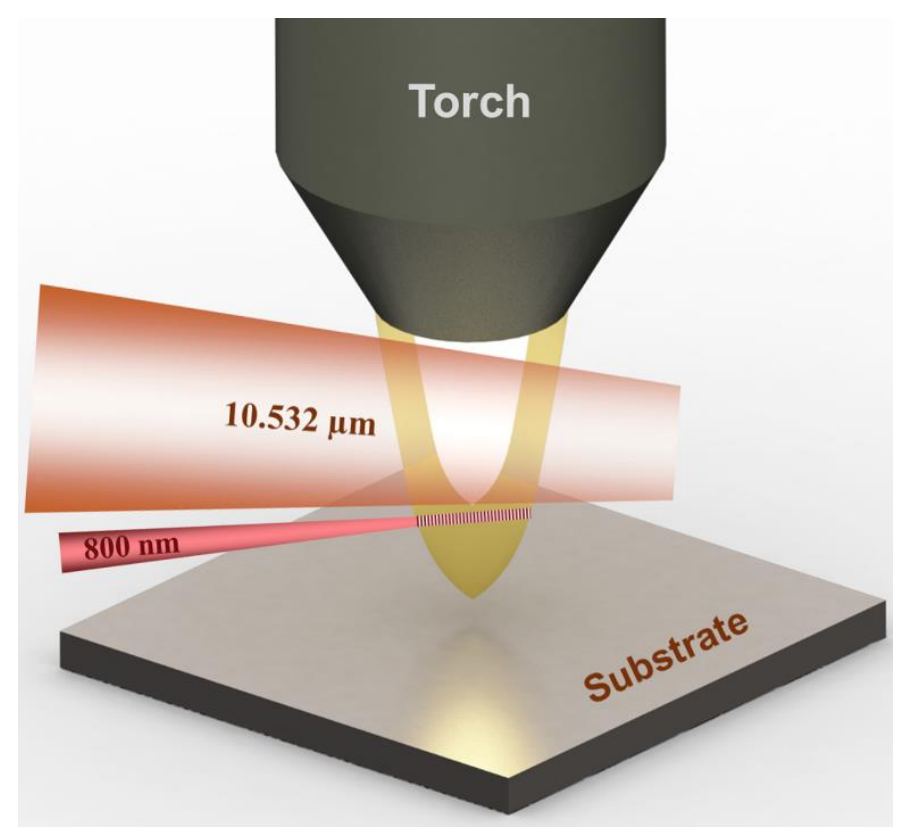

Figure 1. A schematic diagram showing the laser-assisted combustion CVD of diamond and FLIF sensing of flame. 

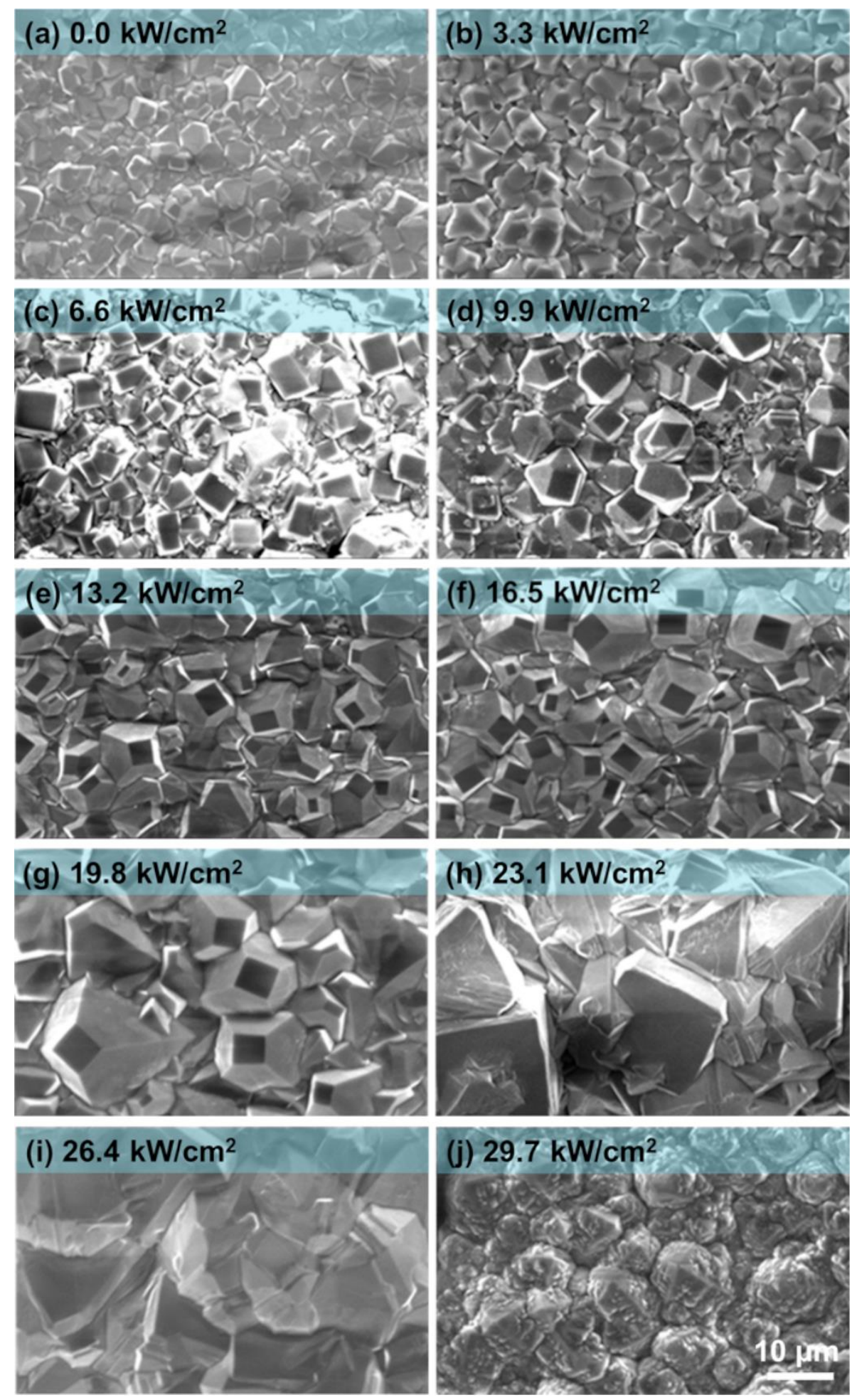

Figure 2. SEM micrographs showing morphologies of the diamond films deposited under different laser power densities from 0.0 to $29.7 \mathrm{~kW} / \mathrm{cm}^{2}$. 


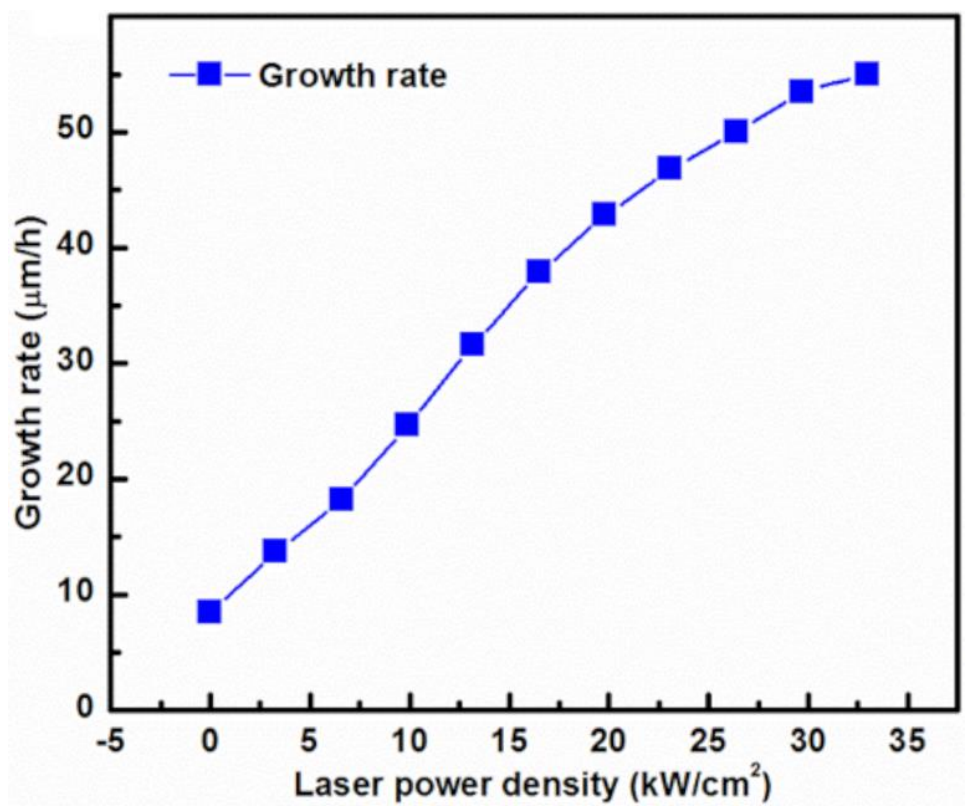

Figure 3. The diagram showing the dependence of the diamond growth rate on the incident $\mathrm{CO}_{2}$ laser power density. 

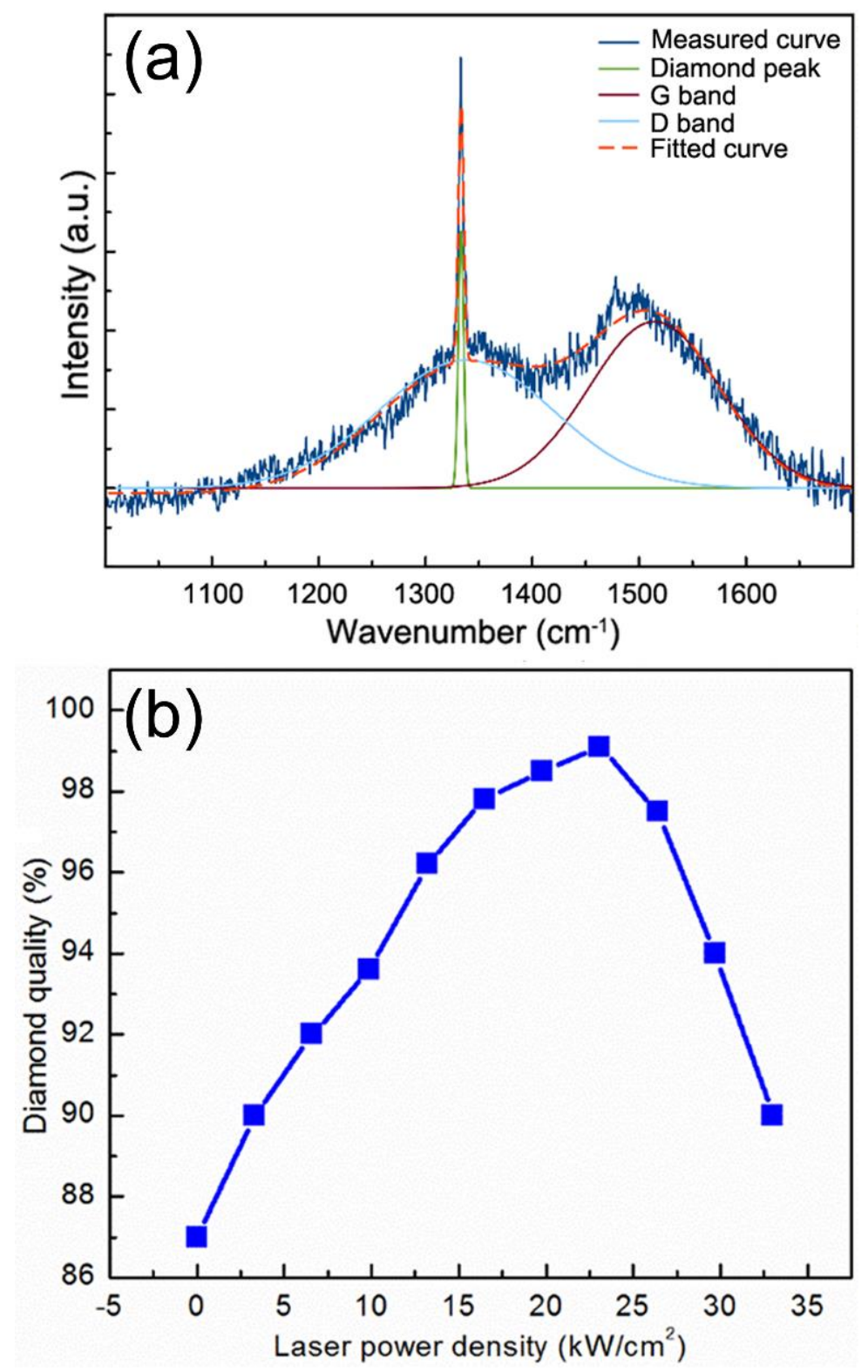

Figure 4. (a) A typical Raman spectrum of the diamond films deposited without resonant laser excitation; and (b) a diagram showing the dependence of the diamond film quality on the incident laser power density. 


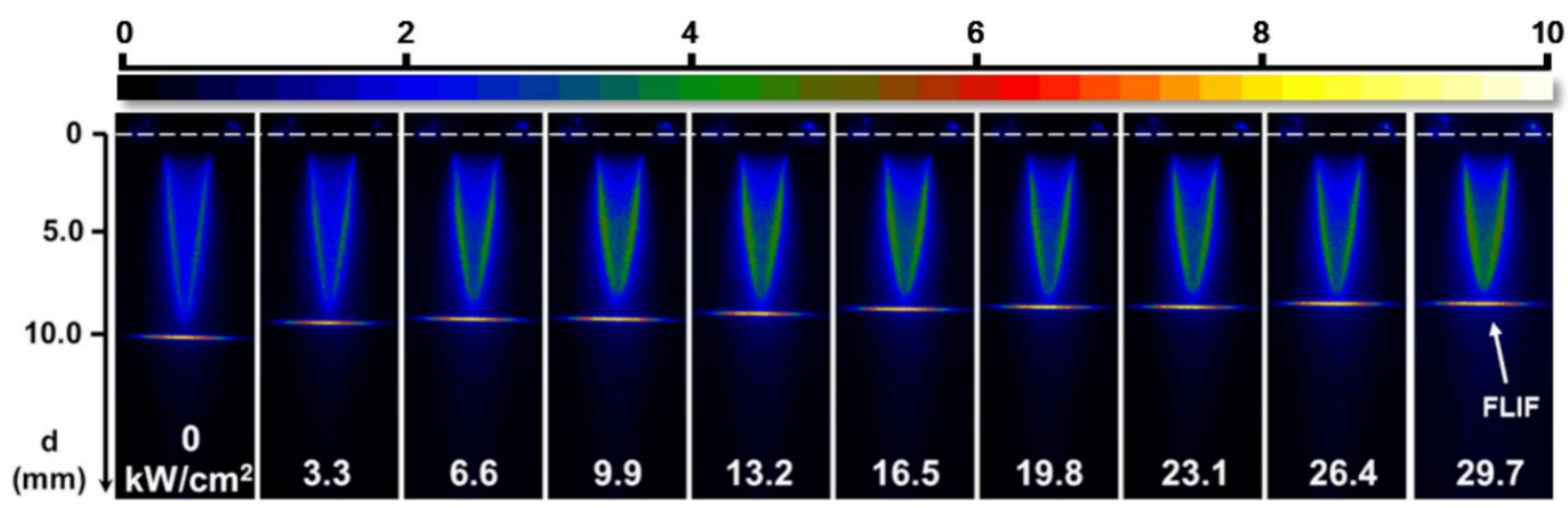

Figure 5. Images of the fs-laser induced filaments in the $\mathrm{O}_{2}-\mathrm{C}_{2} \mathrm{H}_{2}-\mathrm{C}_{2} \mathrm{H}_{4}$ flames under different laser power densities. The dashed line represents the position of the torch nozzle. The scale bar shows the colour and brightness of the flames. 


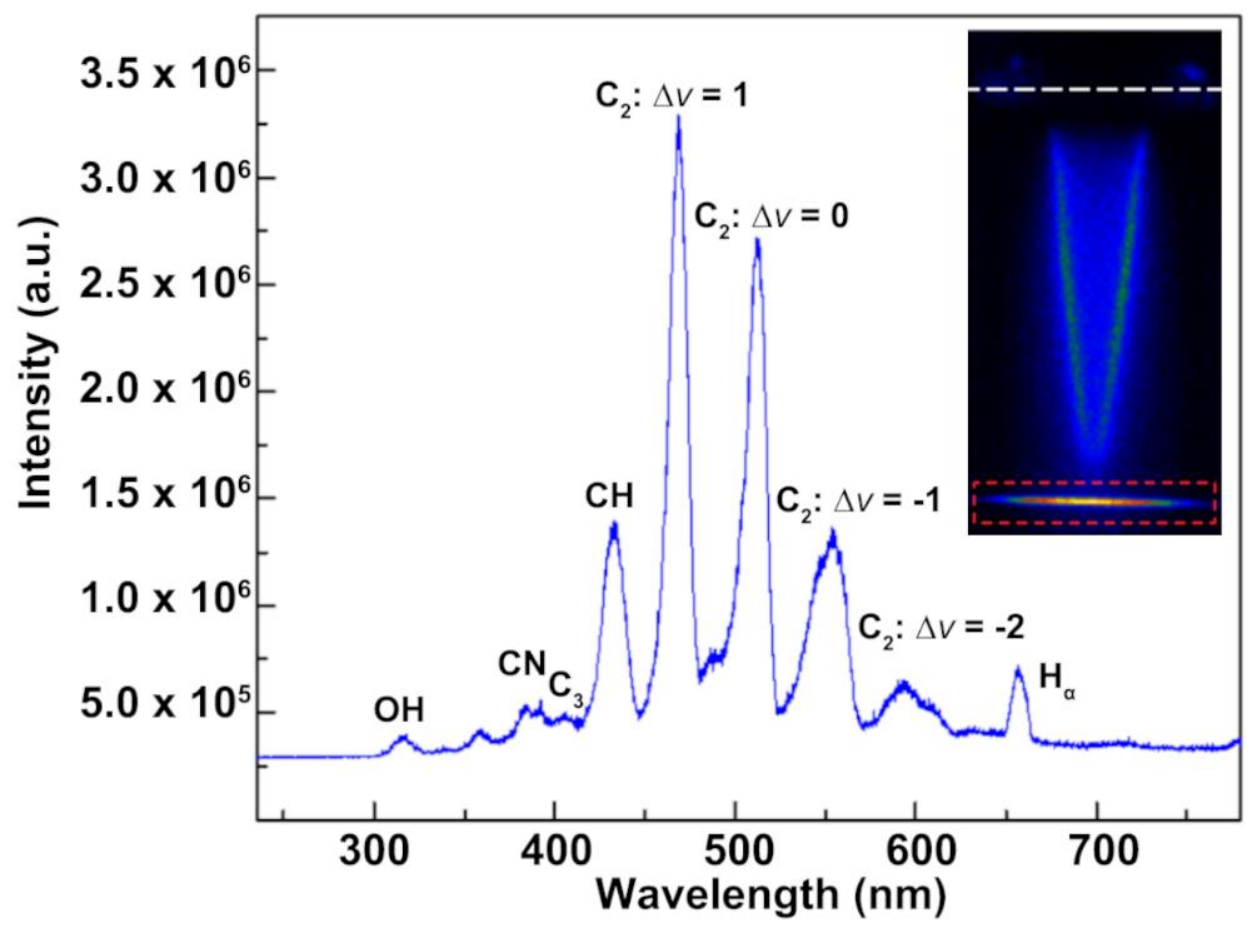

Figure 6. A typical FILF spectrum of the flame filament (as shown in the inset) at the diamond growth region without the vibrational excitation. 


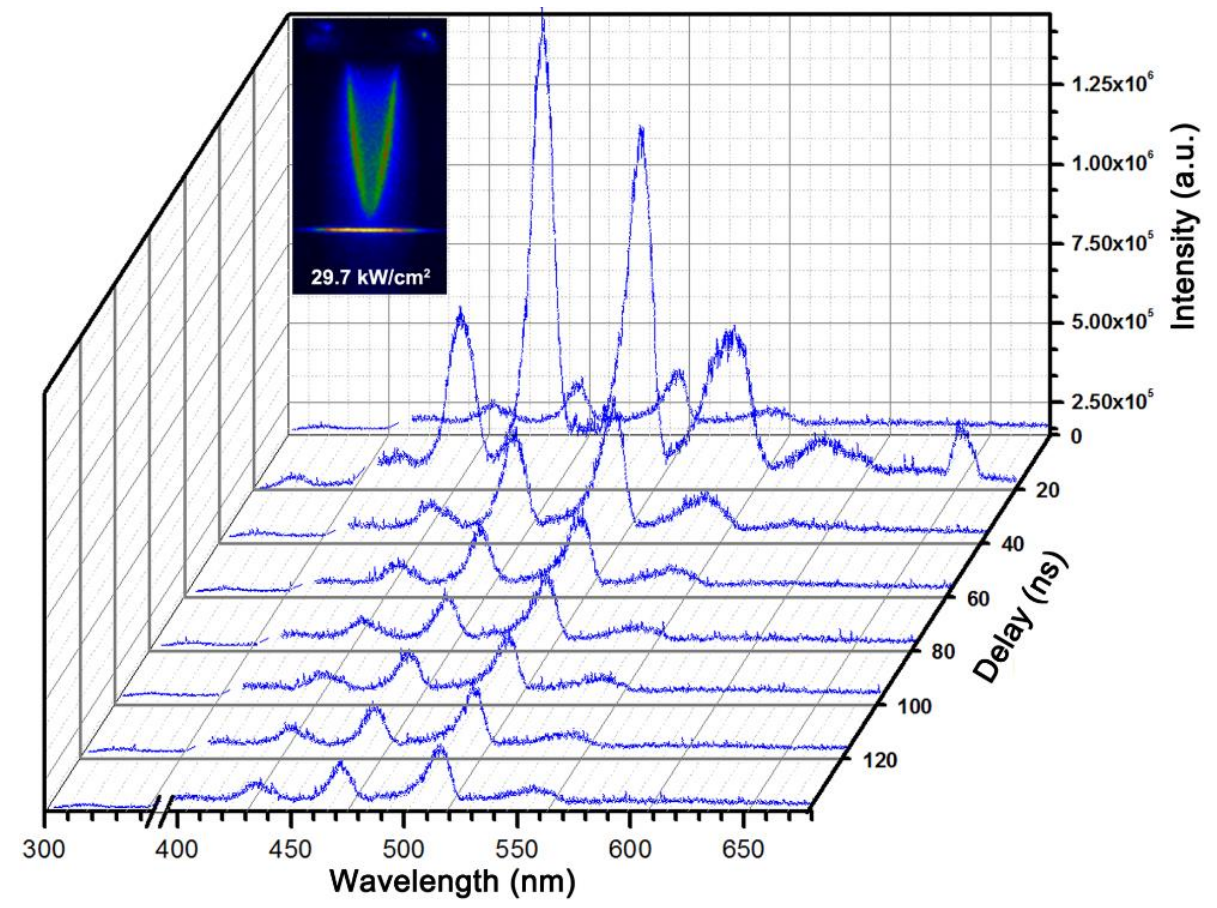

Figure 7. Time resolved spectra of the flame filament (as shown in the inset) induced by fs-laser irradiation at the diamond-formation zone at the $\mathrm{CO}_{2}$ laser power intensity of $29.7 \mathrm{~kW} / \mathrm{cm}^{2}$. 

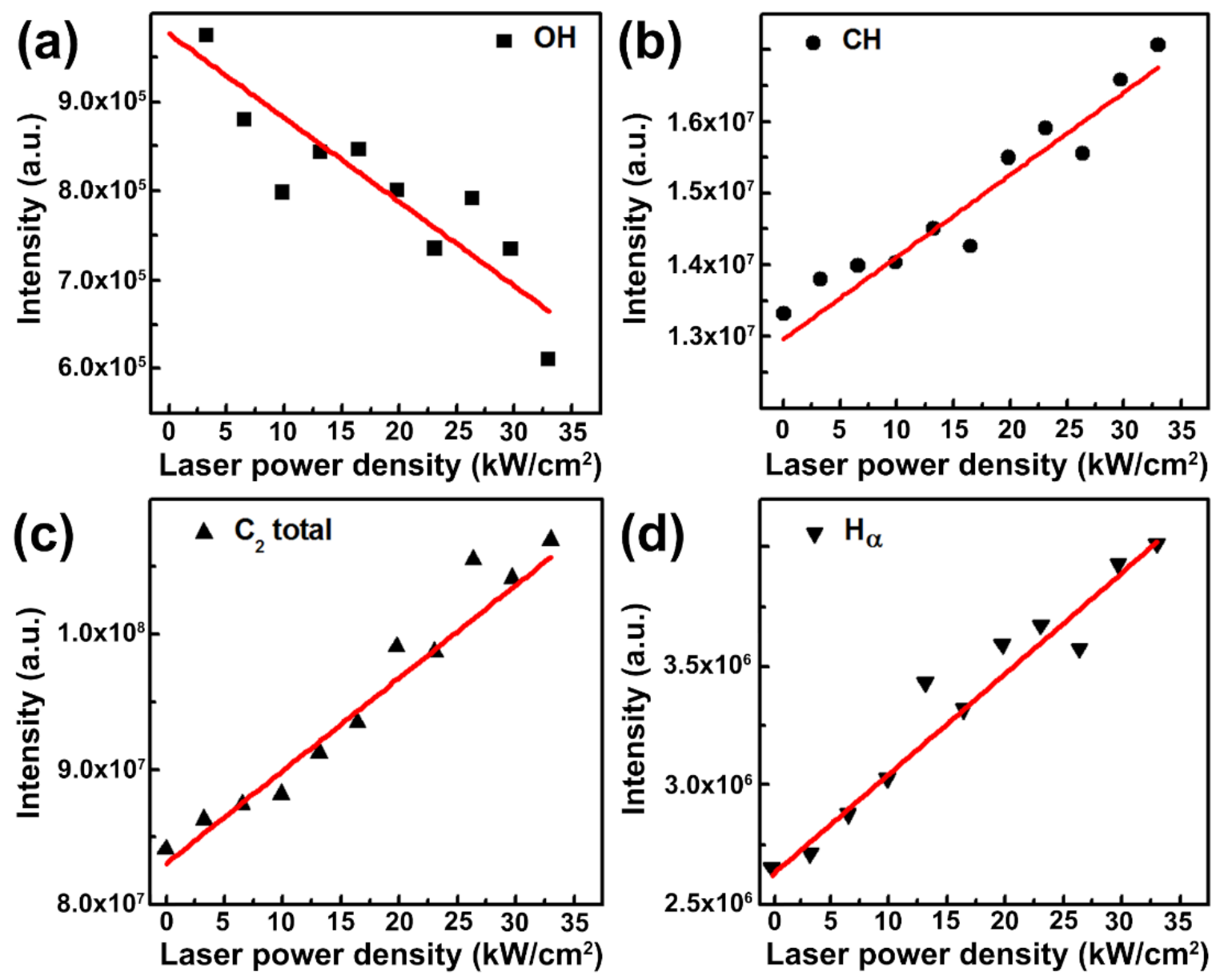

Figure 8. Emission intensities of (a) $\mathrm{OH}$, (b) $\mathrm{CH}$, (c) $\mathrm{C}_{2}$, and (d) $\mathrm{H}_{\alpha}$ with respect to the $\mathrm{CO}_{2}$ laser power density obtained from the FLIF filaments at 40 ns delay time. 


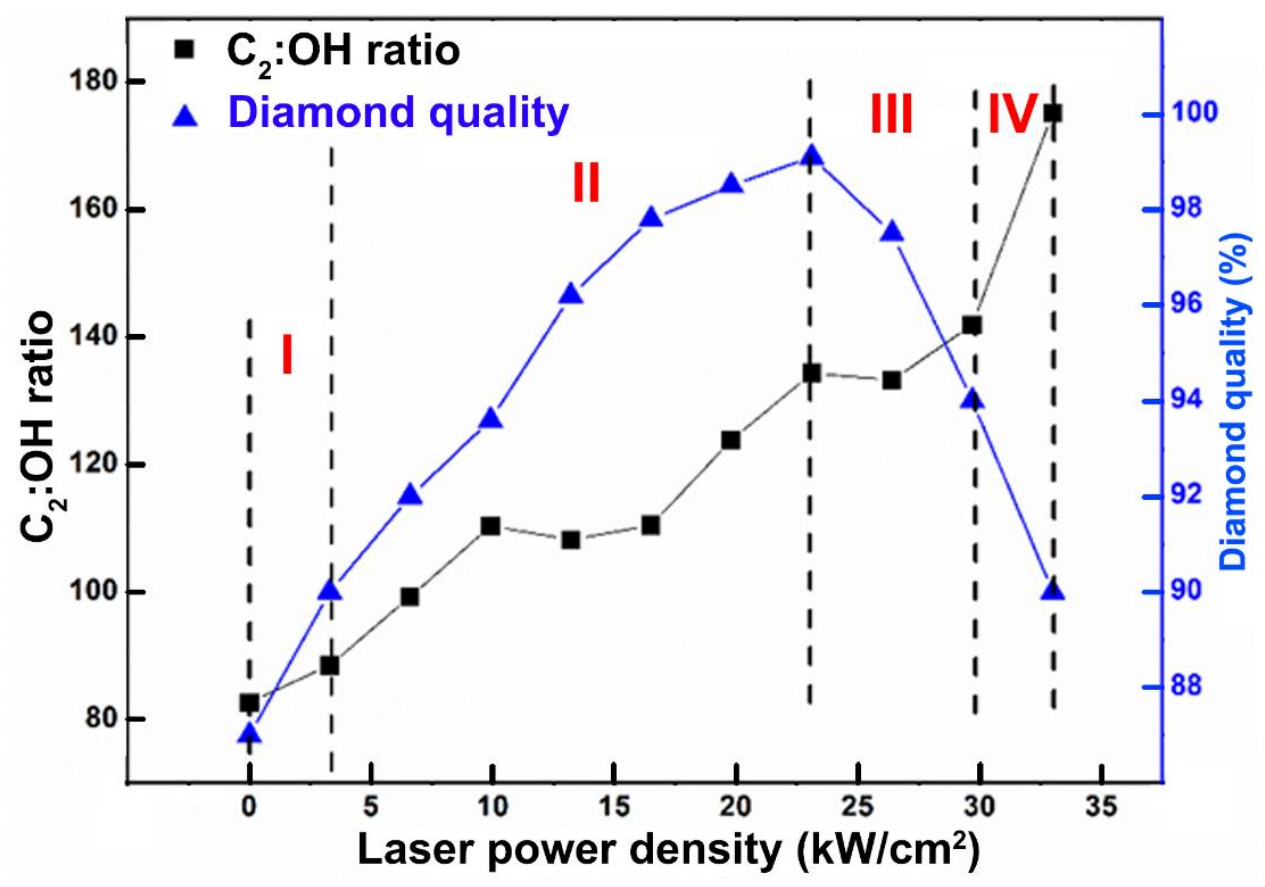

Figure 9. Dependence of $\mathrm{C}_{2}: \mathrm{OH}$ ratio and diamond quality on the $\mathrm{CO}_{2}$ laser power density. 


\section{TABLES}

Table 1. Detected radicals and corresponding transitions. ${ }^{21-25}$

\begin{tabular}{|c|c|c|}
\hline Radical & Transition & Peak (nm) \\
\hline $\mathrm{OH}$ & $\mathrm{A}^{2} \Sigma-\mathrm{X}^{2} \Pi$ & $309.1(\Delta \mathrm{v}=0)$ \\
\hline $\mathrm{CN}$ & $\mathrm{B}^{2} \Sigma^{+}-\mathrm{X}^{2} \Sigma^{+}$ & $388.3(\Delta \mathrm{v}=0), 421.6(\Delta \mathrm{v}=-1)$ \\
\hline $\mathrm{C}_{3}$ & $\mathrm{~A}^{1} \prod_{\mathrm{u}}-\mathrm{X}^{1} \Sigma_{\mathrm{g}}{ }^{+}$ & $405(\Delta \mathrm{v}=0)$ \\
\hline $\mathrm{CH}$ & $\mathrm{A}^{2} \Delta-\mathrm{X}^{2} \prod_{\mathrm{r}}$ & $431.4(\Delta \mathrm{v}=0)$ \\
\hline $\mathrm{C}_{2}$ & $\mathrm{~d}^{3} \prod_{\mathrm{g}}-\mathrm{a}^{3} \prod_{\mathrm{u}}$ & $473.7(\Delta \mathrm{v}=+1), 516.5(\Delta \mathrm{v}=0), 563.6(\Delta \mathrm{v}=-1)$ \\
\hline $\mathrm{H}_{\alpha}$ & $3 \mathrm{p}^{2} \mathrm{P}^{0_{1 / 2}}-2 \mathrm{~s}^{2} \mathrm{~S}_{1 / 2}$ & 656.3 \\
\hline
\end{tabular}

\section{AUTHOR INFORMATION}

\section{Corresponding Author}

*Tel.: +1-402-472-8323. Fax: +1-402-472-4732. Email: ylu2@unl.edu.

\section{Author Contributions}

The manuscript was prepared through contributions of all authors. All authors have given approval to the final version of the manuscript. ${ }^{\top}$ These authors, Yun Shen Zhou and Meng Meng Wang, contributed equally to this manuscript. Dr. Yun Shen Zhou composed the manuscript, prepared the figures, and conducted data analysis \& discussion. Meng Meng Wang, a graduate student, contributed to the experiments and data collection. Yao $\mathrm{Lu}$, a graduate student, contributed to the FILF spectroscopic studies. Dr. Jean-François Silvain provides essential 
information on diamond film analysis. Dr. Yong Feng Lu is the corresponding author who supervised the project and conceived the idea.

\section{Funding Sources}

National Science Foundation (CMMI 1265122 and 1129613)

Office of Naval Research (N00014-09-7581-0943).

\section{ACKNOWLEDGMENT}

The authors gratefully appreciate the financial supports from National Science Foundation (CMMI 1129613 and 1068510) and Office of Naval Research (N00014-09-7581-0943). In addition, the authors would like to express our appreciation towards Dr. D. R. Alexander in the Department of Electrical \& Computer Engineering at the University of Nebraska-Lincoln for providing convenient access to the SEM.

\section{ABBREVIATIONS}

FLIF, femtosecond laser-induced filamentation; HPHT, high pressure high temperature; HFCVD, hot filament chemical vapour deposition; MWCVD, microwave chemical vapour deposition; CVD, chemical vapour deposition; OES, optical emission spectroscopy; fs, femtosecond; WC, tungsten carbide; ICCD, intensified charge-coupled device; SEM, scanning electron microscope. 


\section{REFERENCES}

(1) Railkar, T. A.; Kang, W. P.; Windischmann, H.; Malshe, A. P.; Naseem, H. A.; Davidson, J. L.; Brown, W. D., A critical review of chemical vapor-deposited (CVD) diamond for electronic applications. Crit Rev Solid State 2000, 25, 163-277.

(2) Lee, S. T.; Lin, Z. D.; Jiang, X., CVD diamond films: nucleation and growth. Mat Sci Eng $R$ 1999, 25, 123-154.

(3) Markham, M. L.; Dodson, J. M.; Scarsbrook, G. A.; Twitchen, D. J.; Balasubramanian, G.;

Jelezko, F.; Wrachtrup, J., CVD diamond for spintronics. Diamond and Related Materials 2011, 20, 134-139.

(4) Matsumoto, S., Development of diamond synthesis techniques at low pressures. Thin Solid Films 2000, 368, 231-236.

(5) Marinkovic, S. N., Diamond synthesized at low pressure. Chem Phys Carbon 2004, 29, 71207.

(6) Schwander, M.; Partes, K., A review of diamond synthesis by CVD processes. Diamond and Related Materials 2011, 20, 1287-1301.

(7) Zhu, W.; Tan, B. H.; Tan, H. S., Diamond Thin-Films Synthesized by a Multinozzle OxyAcetylene Chemical-Vapor-Deposition Method. Thin Solid Films 1993, 236, 106-110. 
(8) Xie, Z. Q.; Zhou, Y. S.; He, X. N.; Gao, Y.; Park, J.; Ling, H.; Jiang, L.; Lu, Y. F., Fast Growth of Diamond Crystals in Open Air by Combustion Synthesis with Resonant Laser Energy Coupling. Crystal Growth \& Design 2010, 10, 1762-1766.

(9) Xie, Z. Q.; He, X. N.; Hu, W.; Guillemet, T.; Park, J. B.; Zhou, Y. S.; Bai, J.; Gao, Y.; Zeng, X. C.; Jiang, L.; Lu, Y. F., Excitations of Precursor Molecules by Different Laser Powers in Laser-Assisted Growth of Diamond Films. Crystal Growth \& Design 2010, 10, 4928-4933.

(10) Wang, M.; Zhou, Y. S.; Xie, Z. Q.; Gao, Y.; He, X. N.; Jiang, L.; Lu, Y. F., Seed-free growth of diamond patterns on silicon predefined by femtosecond laser direct writing. Crystal Growth \& Design 2013, 13, 716-722.

(11) Zhou, Y. S.; Fan, L. S.; Xie, Z. Q.; Jiang, L.; Silvain, J. F.; Lu, Y. F., Laser-assisted vibrational control of precursor molecules in diamond synthesis. Curr Opin Solid St M 2015, 19, 107-114.

(12) Fan, L. S.; Zhou, Y. S.; Wang, M. X.; Gao, Y.; Liu, L.; Silvain, J. F.; Lu, Y. F., Resonant vibrational excitation of ethylene molecules in laser-assisted diamond deposition. Laser Phys Lett 2014, 11, 076002.

(13) He, X. N.; Shen, X.; Gebre, T.; Xie, Z. Q.; Jiang, L.; Lu, Y., Spectroscopic determination of rotational temperature in $\mathrm{C} 2 \mathrm{H} \mathrm{4/C} 2 \mathrm{H} \mathrm{2/O} 2$ flames for diamond growth with and without tunable CO 2 laser excitation. Applied optics 2010, 49, 1555-1562.

(14) Couairon, A.; Mysyrowicz, A., Femtosecond filamentation in transparent media. Physics Reports 2007, 441, 47-189.

(15) Chin, S. L., Femtosecond laser filamentation. ed.; Springer: 2010; Vol. 55. 
(16) Xu, H. L.; Chin, S. L., Femtosecond Laser Filamentation for Atmospheric Sensing. Sensors 2010, 11, 32-53.

(17) Li, H.-L.; Xu, H.-L.; Yang, B.-S.; Chen, Q.-D.; Zhang, T.; Sun, H.-B., Sensing combustion intermediates by femtosecond filament excitation. Optics Letters 2013, 38, 1250-1252.

(18) Li, H.-L.; Wei, X.-Y.; Xu, H.-L.; Chin, S.-L.; Yamanouchi, K.; Sun, H.-B., Femtosecond laser filamentation for sensing combustion intermediates: A comparative study. Sensors and Actuators B: Chemical 2014, 203, 887-890.

(19) Bąk, G. W.; Fabisiak, K.; Klimek, L.; Kozanecki, M.; Staryga, E., Investigation of biaxial stresses in diamond films deposited on a silicon substrate by the HF CVD method. Optical Materials 2008, 30, 770-773.

(20) Sails, S. R.; Gardiner, D. J.; Bowden, M.; Savage, J.; Rodway, D., Monitoring the quality of diamond films using Raman spectra excited at $514.5 \mathrm{~nm}$ and $633 \mathrm{~nm}$. Diamond and Related Materials 1996, 5, 589-591.

(21) Niemax, K., Analytical Atomic Laser Spectroscopy. Fresen Z Anal Chem 1987, 327, 6-7.

(22) Turk, G. C.; Travis, J. C., Simultaneous detection of laser-enhanced ionization and laserinduced fluorescence in flames: noise correlation studies. Spectrochim Acta B 1990, 45, 409-419.

(23) Sutton, G.; Levick, A.; Edwards, G.; Greenhalgh, D., A combustion temperature and species standard for the calibration of laser diagnostic techniques. Combust Flame 2006, 147, 3948.

(24) Firchow, S. J.; Menningen, K. L., Radical density measurements in an atmospheric pressure oxyacetylene torch. Journal of Physics D: Applied Physics 1999, 32, 937-941. 
(25) Welter, M. D.; Menningen, K. L., Radical density measurements in an oxyacetylene torch diamond growth flame. J Appl Phys 1997, 82, 1900-1904.

(26) Ikeda, M.; Ito, H.; Hiramatsu, M.; Hori, M.; Goto, T., Effects of H, OH, and CH3 radicals on diamond film formation in parallel-plate radio frequency plasma reactor. J Appl Phys 1997, 82, 4055-4061.

(27) Bohr, S.; Haubner, R.; Lux, B., Influence of nitrogen additions on hot-filament chemical vapor deposition of diamond. Appl Phys Lett 1996, 68, 1075-1077.

(28) Badzian, A.; Badzian, T.; Lee, S. T., Synthesis of diamond from methane and nitrogen mixture. Appl Phys Lett 1993, 62, 3432-3434.

(29) Gruen, D. M.; Liu, S. Z.; Krauss, A. R.; Pan, X. Z., Buckyball Microwave Plasmas Fragmentation and Diamond-Film Growth. J Appl Phys 1994, 75, 1758-1763.

(30) Gruen, D. M.; Liu, S. Z.; Krauss, A. R.; Luo, J. S.; Pan, X. Z., Fullerenes as Precursors for Diamond Film Growth without Hydrogen or Oxygen Additions. Appl Phys Lett 1994, 64, 15021504.

(31) Valeur, B.; Berberan-Santos, M. N., Molecular fluorescence: principles and applications. ed.; John Wiley \& Sons: 2012.

(32) Liu, T.; Raabe, D.; Mao, W.; Zaefferer, S., Microtexture and Grain Boundaries in Freestanding CVD Diamond Films: Growth and Twinning Mechanisms. Advanced Functional Materials 2009, 19, 3880-3891. 


\section{Spectroscopic sensing of $\mathrm{O}_{2}-\mathrm{C}_{2} \mathrm{H}_{2}-\mathrm{C}_{2} \mathrm{H}_{4}$ flames for diamond growth using femtosecond filamentation}

Yun Shen Zhou, Meng Meng Wang, Yao Lu, Jean François Silvain, and Yong Feng Lu

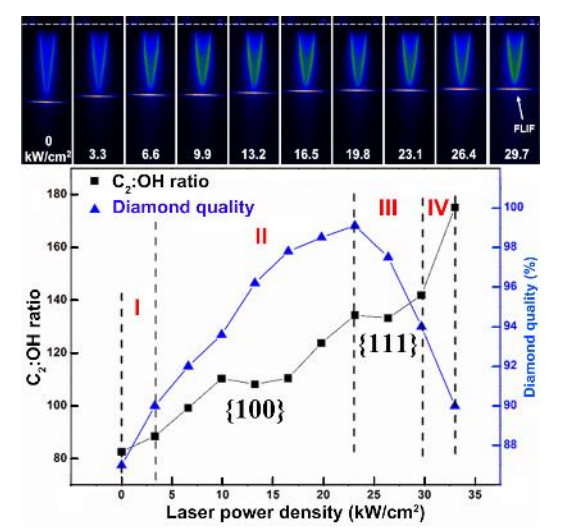

Based on the femtosecond laser-induced filamentation (FLIF) spectroscopic investigations, it is found that growing diamond crystals of preferential orientations depends highly on $\mathrm{C}_{2}: \mathrm{OH}$ ratio. At the $\mathrm{C}_{2}: \mathrm{OH}$ ratio around $110.00,\{100\}$ oriented diamond crystals are preferentially grown. While at the $\mathrm{C}_{2}: \mathrm{OH}$ ratio around $133.34,\{111\}$ oriented diamond crystals are preferentially grown. 